\title{
ENVIRONMENTAL IMPACT ASSESSMENT \\ FOR TRANSPORTATION CORRIDORS USING GIS
}

\author{
By \\ Iqbal Ahmed \\ B.Eng. (Civil), Bangladesh Engineering University, 1992
}

\begin{abstract}
A project report
presented to Ryerson University in partial fulfillment of the requirements for the degree of Master of Engineering in the Program of Civil Engineering
\end{abstract}

Toronto, Ontario, Canada, 2005

(C) Iqbal Ahmed, 2005 
UMI Number: EC52999

\section{All rights reserved \\ INFORMATION TO USERS}

The quality of this reproduction is dependent upon the quality of the copy submitted. Broken or indistinct print, colored or poor quality illustrations and photographs, print bleed-through, substandard margins, and improper alignment can adversely affect reproduction.

In the unlikely event that the author did not send a complete manuscript and there are missing pages, these will be noted. Also, if unauthorized copyright material had to be removed, a note will indicate the deletion.

\section{$\mathrm{UMI}^{\circ}$}

UMI Microform EC52999

Copyright 2008 by ProQuest LLC

All rights reserved. This microform edition is protected against unauthorized copying under Title 17, United States Code.

ProQuest LLC

789 East Eisenhower Parkway

P.O. Box 1346

Ann Arbor, Ml 48106-1346 


\begin{abstract}
AUTHOR'S DECLARATION
I hereby declare that I am the sole author of this project report, I authorize Ryerson University to lend this project report to other institutions or individuals for the purpose of scholarly research,
\end{abstract}

Iqbal Ahmed

Department of Civil Engineering

Ryerson University

I further authorize Ryerson University to reproduce this project report by photocopying or by other means, in total or in part, at the request of their institutions or individuals for the purpose of scholarly research.

Iqbal Ahmed

Department of Civil Engineering

Ryerson University 


\section{BORROWER'S}

Ryerson University requires the signatures of all persons using or photocopying this project report. Please sign below and give address and date.

\begin{tabular}{|c|c|c|c|}
\hline Name & Address & Signature & Date \\
\hline & & & \\
\hline & & & \\
\hline & & & \\
\hline & & & \\
\hline & & & \\
\hline & & & \\
\hline & & & \\
\hline & & & \\
\hline & & & \\
\hline & & & \\
\hline & & & \\
\hline & & & \\
\hline & & & \\
\hline & . & & \\
\hline & & & \\
\hline & & & \\
\hline & & & \\
\hline & & & \\
\hline & & & \\
\hline & & & \\
\hline & & & \\
\hline
\end{tabular}




\section{Ryerson University \\ School of Graduate Studies}

The undersigned certify that they have read, and recommend to the School of Graduate Studies for acceptance, a project entitled "Environmental Impact Assessment for Transportation Corridors using GIS Tool" submitted in partial fulfillment of the requirements for the degree of Master of Engineering.

\begin{tabular}{|r|r|}
\hline & Supervisor \\
& Department of Civil Engineering \\
\hline & Department of Civil Engineering \\
\hline & Date \\
\hline
\end{tabular}




\author{
ABSTRACT \\ Environmental Impact Assessment for Transportation Corridors using GIS \\ Master of Engineering, 2005 \\ By Iqbal Ahmed \\ Department of Civil Engineering \\ Ryerson University
}

\begin{abstract}
An environmental impact study is the significant part of any transportation project development. In general environmental assessment is a process to find out the possible impact on environments due to the effects of proposed initiatives before they are carried out. In transportation sector, construction of new roads or highways may minimize congestion and reduce travel path and time but may also have an effect on environment. So it is necessary to develop the best alternative routes so that natural, cultural, social environmental impacts are minimized. In recent years geographic information systems (GIS) have become increasing popular for environmental studies. GIS can play a vital role for analysis and in formulating the quick mitigation plans for high-risk environments. This study is articulates what environmental impacts need to be assessed in transportation corridor planning, what geospatial data are needed to support these identified impact assessment activities, and how and what GIS tools are required to facilitate the corresponding assessment activities. The Mid-Peninsula Transportation Corridor (MPTC) planning project is analyzed as a case study.
\end{abstract}




\section{ACKNOWLEDGEMENTS}

I would like to express my deep gratitude to my supervisor, Prof. Songnian Li from the Department of Civil Engineering, Ryerson University for his attentive and comprehensive supervision, without which the completion of this study would have been difficult.

My special thanks go to Dr. Jonathan $\mathrm{Li}$, whose course on Geospatial Modelling and Visualization is a good resource for me. I also want to emphasise valuable assistance of the Ryerson staff for providing me with their help during the academic years.

Many thanks to my friends, specially Khushnud, Eric and Mafruha, for their enormous support, which encouraged me to the completion of this study. 


\section{DEDICATION}

To my father 


\section{TABLE OF CONTENTS}

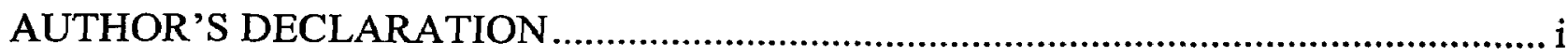

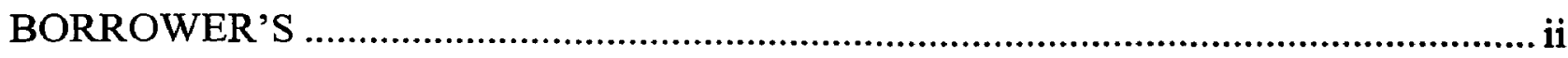

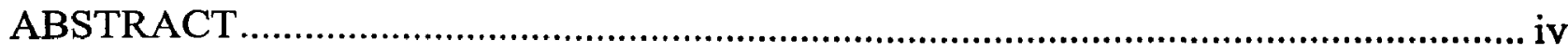

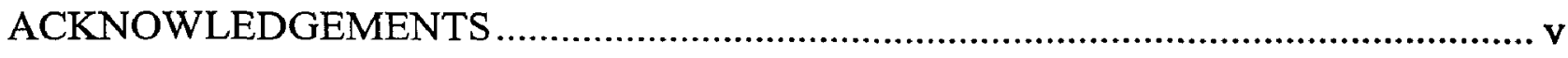

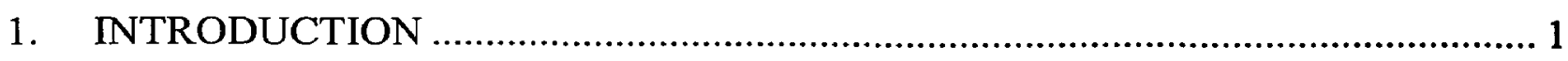

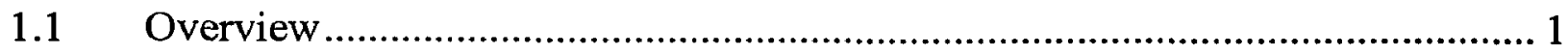

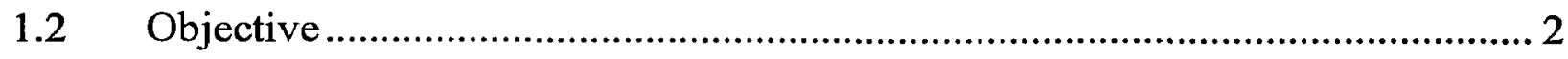

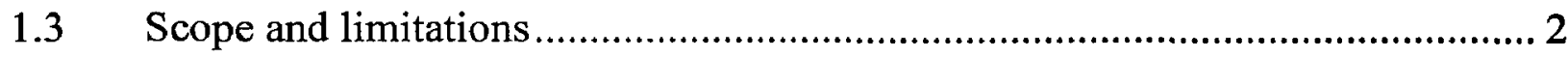

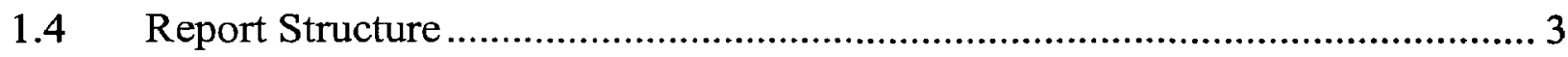

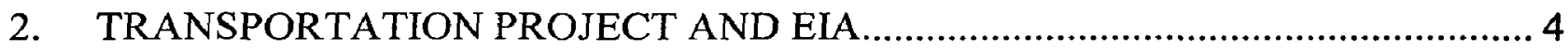

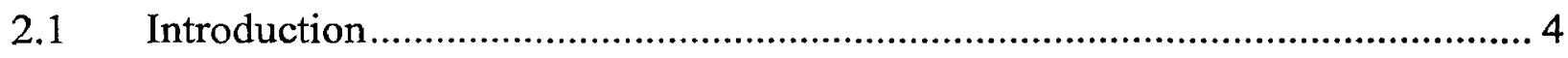

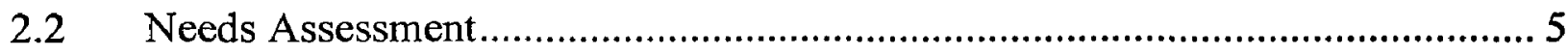

$2.3 \quad$ Environmental Impact Assessment (EIA) ……................................................. 6

2.4 The Potential Environmental Effects for MPTC …......................................... 14

$2.5 \quad$ EIA and Road Planning …...................................................................... 16

2.6 EIA at Different Stages of Road Planning..................................................... 17

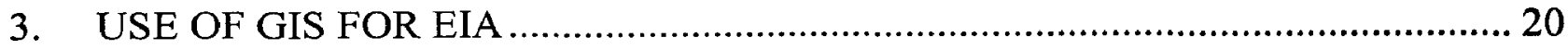

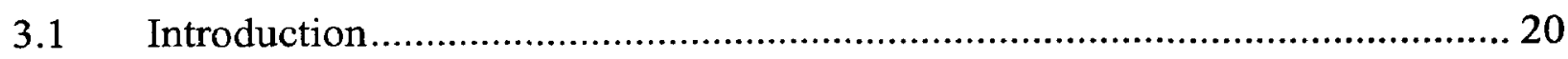

3.2 The Integration of GIS into EIA ………….............................................. 22

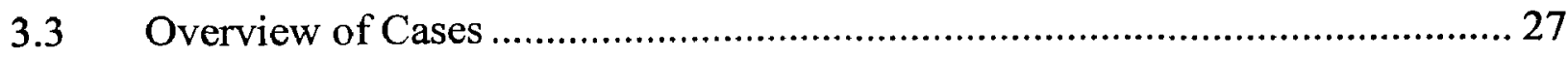

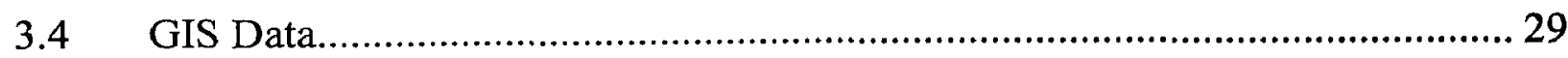

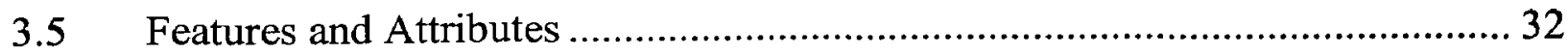

3.6 Benefits of Using GIS to Perform EIA ….................................................... 33

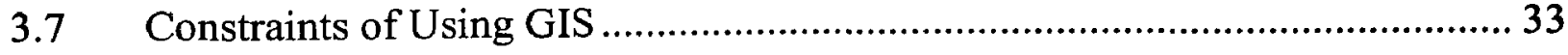

4. STUDY CASE: MID-PENINSULA TRANSPORTATION CORRIDOR ............... 34

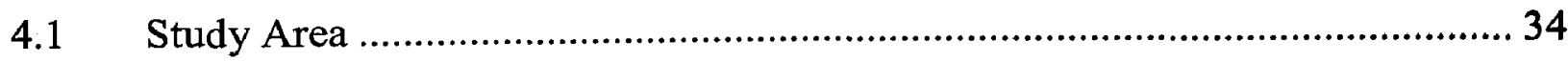

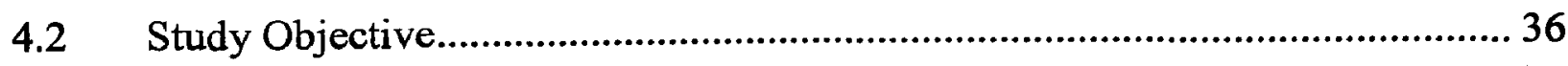




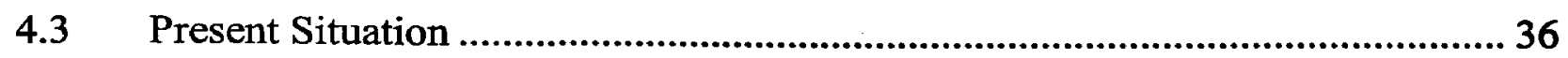

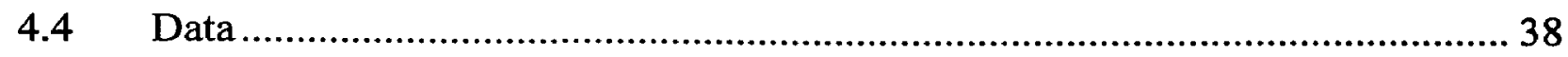

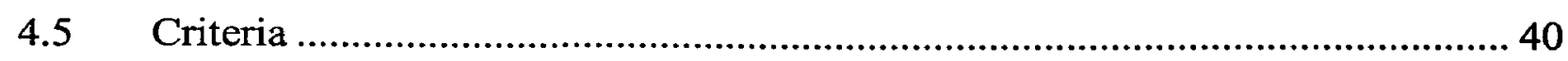

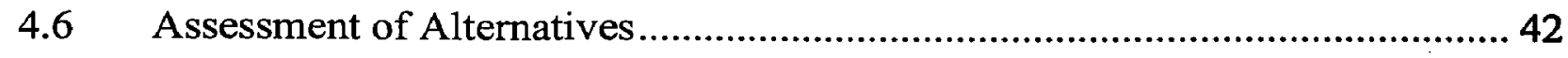

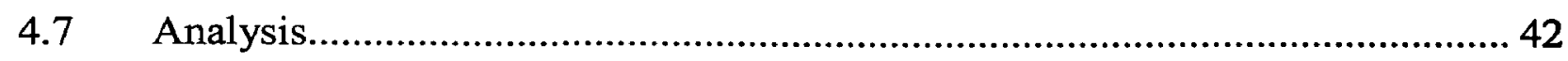

4.7.1 Analysis 1 - Municipality Areas Conflict ............................................... 42

4.7.2 Analysis 2 - Transportation of Dangerous Goods........................................ 43

4.7.3 Analysis 3 - Landuse Conflicts .................................................................... 45

4.7.4 Analysis 4 - Hydrography …............................................................... 47

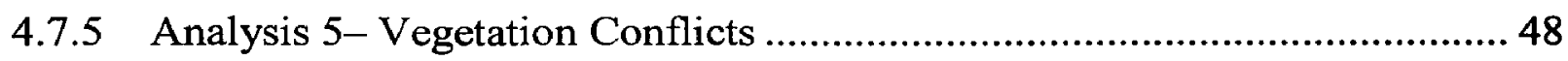

4.7.6 Analysis 6- Educational Institute ............................................................ 51

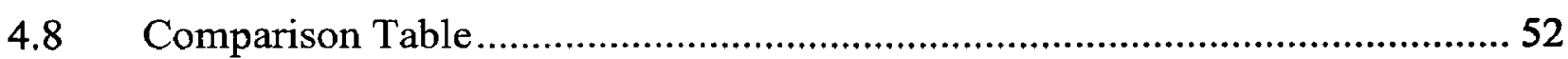

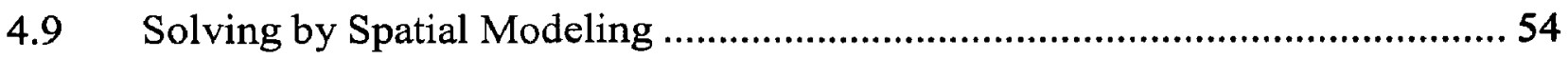

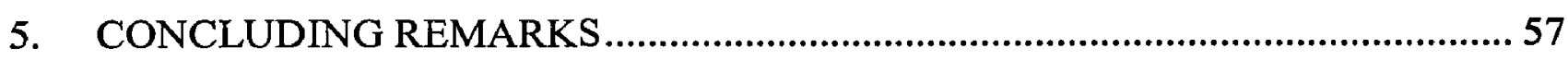

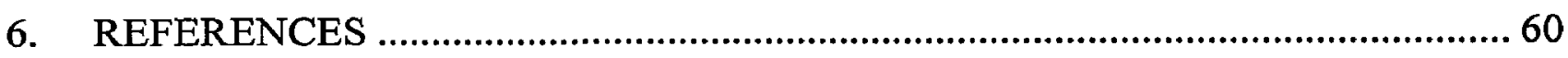




\section{LIST OF FIGURES}

Figure 1 Schema for the process of environmental impact assessment........................ 11

Figure 2 The main actors in EIA process............................................................... 13

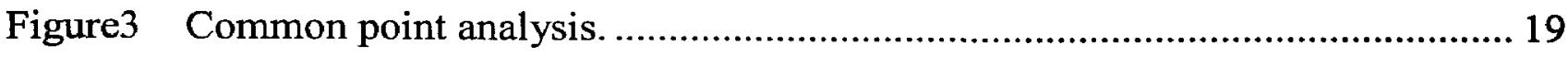

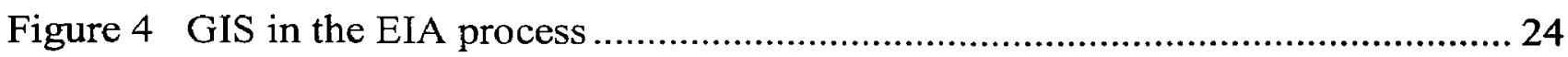

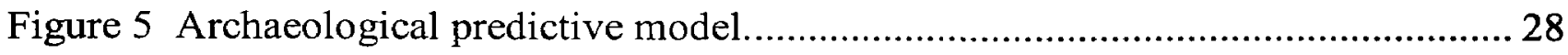

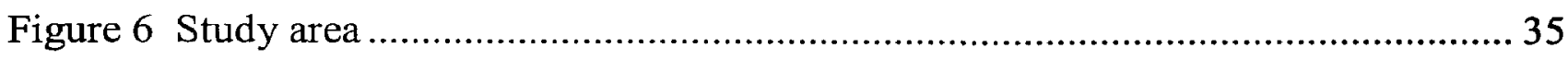

Figure 7 Existing natural and landuse layer of study area.............................................39

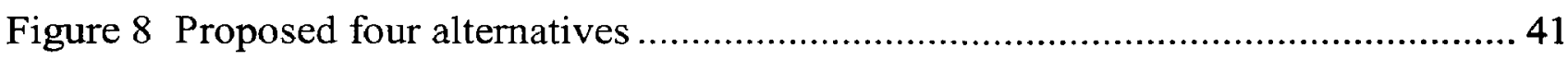

Figure 9 Graphical representations of affected municipality and population.................. 43

Figure 10 The zone of risk due to accident has a buffer of 500 meters.......................... 44

Figure 11 Graph showing the number of affected municipality and streamline...............45

Figure 12 Distribution of different land use classes within the corridor Alt-1 ...............46

Figure 13 Land use classes shown in graph for different alternatives............................ 47

Figure 14 Numbers of affected stream lines are shown in graphs................................... 48

Figure 15 Affected vegetation area due to construction of new corridor. ........................ 49

Figure 16 Graphical representation of affected vegetation............................................ 50

Figure 17 Number of affected wetland is shown in graphs. ........................................ 50

Figure 18 Attribute tables of affected institutions for Alt-1 . ....................................... 51

Figure 19 Number of affected institutions is shown in graphs. .....................................51

Figure 20 Corridor site selection process.................................................................... 55

Figure 21 Suitable location for corridor....................................................................... 56 


\section{LIST OF TABLES}

Table 1 Components of the environment.............................................................. 31

Table 2 Proposed route generation data................................................................ 38

Table 3 Impacts associated with alternatives.................................................... 52 


\section{INTRODUCTION}

\subsection{Overview}

Environmental Impact Assessment (EIA) is essentially an approach to conceiving, planning, designing, implementing and adjusting undertakings in a way that takes full account of environmental factors including the socioeconomic and biophysical ones(Gibson, 2004).

An environmental impact study is the significant part of any transportation project development. It is a process to find out the possible impact on environments due to the effects of proposed initiatives before they are carried out. In transportation sector, construction of new road or highway may minimize congestion and reduce travel path and time but may also an effect on environment. So it is necessary to develop a system so that natural, cultural, social and environmental impacts are minimized.

To determine EIA a lot of information and spatial data about the studying objects and facilities should be collected and analyzed. The conventional way of EIA study is a less accurate and more time consuming process because it has more dependant and independent variables, which have to be taken into account (e.g., land use, land price, population density, socio economic level, road accessibility, railway accessibility, air quality, ground water quality, noise level, biological content, historical value, archeological and visual importance), which also have different consequences. There needs to be a tool or support system, which can handle the larger volume of spatial and non-spatial data and which is capable of doing complex analysis and produce an alternative plan. Geographic Information Systems (GIS) are the latest technologies and tools, which can produce much more accurate results quickly and effectively. GIS have been described as computer-assisted systems for the capture, storage, retrieval, analysis, and display of spatial data (Clarke, 1986).

In this report the Mid-Peninsula Transportation Corridor (MPTC) planning project is analyzed as a case study. In the context of the Niagara Peninsula Transportation corridor, the application of the Ontario Environmental Assessment Act (EAA) to the project was intended to ensure: "The betterment of the people of the whole or any part of Ontario by providing for 
the protection, conservation and wise management in Ontario of the environment". Here GIS is addressed and discussed as a method which gives the power of working with spatial information to find best alternatives of the Mid-Peninsula Transportation Corridor from the four preset alternatives.

\subsection{Objective}

Geographical Information System (GIS) provides an efficient technique for managing geographical information. Using GIS in road planning may significantly improve the result of EIA. The EIA process will confirm the transportation problems and opportunities, and develop and evaluate potential solutions. Environmental impact assessment of the Niagara Mid-Peninsula Transportation Corridor is taken as a case study of this report and the main objectives are:

- To introduce the concept of GIS as a tool for outlining the significant environmental impacts that can be caused by construction of the transport corridor.

- To develop a GIS based analysis system and present a comparison table of the impacts from various alternative corridors to decision-makers and the public.

\subsection{Scope and limitations}

This study has demonstrated overlay techniques to assessments of environmental impact from many sources of data. All analyses in the report are performed by applying GIS method on the four preset alternatives of the proposed Niagara Mid-Peninsula Transportation Corridor to find out the best alternative. However the current situation is that MTO (Ministry of Transportation, Ontario) yet has not finalized the preferred corridor. They will consult with the community on the needs assessment study findings and complete an environmental assessment (federal and provincial) to determine the preferred route location for the Mid Peninsula Transportation Corridor. So result of this study was not compared with the actual road corridor. 


\subsection{Report Structure}

This report consists of five chapters including an introduction and conclusion. Following the introduction the second chapter provides an overview of transportation projects and its impact on environment and a brief description about EIA and discussed all the issues that have been taken into account to avoid or minimize impacts for capturing potential benefits. Third chapter narrows down the GIS applications in EIA and benefits of using GIS to perform EIA. Fourth chapter focuses on case study for the Mid-Peninsula Transportation Corridor (MPTC). In this chapter a basic description of the project purpose and location and GIS tasks on environmental information for all alternative corridors are analyzed. Finally, concluding remarks are presented in the fifth chapter. 


\section{TRANSPORTATION PROJECT AND EIA}

\subsection{Introduction}

Transportation networks play a vital role in contributing to the economic development of nations and enhance the quality of life of its citizens; it has also been a major contributor to the degradation of the environment. With an ever increasing population, there is a constant demand for new highway infrastructure. With the emergence of a more environmentally sound population there has been an increase in public awareness as to how and where these new highways are being located. This is because roads can have the negative effect of fragmenting previously large patches of habitat into smaller ones by creating a barrier to movement (Alexander, et al., 2000). The process of environmental impact assessment was developed as an effective planning tool to improve, conserve and protect the environment due to transportation.

In this report environmental impact associated with the Mid-Peninsula Transportation Corridor has been discussed. MTO is undertaking the planning and environmental assessment study for the proposed MPTC. The EA Terms of Reference is the first step in the formal EA process. If MOE approves the ToR, then the next step is the selection of preferred route location. After EA is approved, MTO can designate the route, protect property and proceed with detail design and EA work required prior to construction of the facility. The overall planning and EA process takes at least 8-10 years. The actual timing of construction will be dependent on government priorities and the availability of funding. The EA study to determine a preferred route and subsequent protection by the province is a key step in providing the required certainty for municipalities to proceed with land use planning as well as certainty for affected residents. A definite impact assessment for any of such type of development should be studied to safeguard the environment. Transportation planners, land use planners, transportation engineers, and environmental specialists must consider environmental impacts when planning or designing a transportation project. It is important that these individuals understand why environmental planning is necessary, how the impact must be analyzed and what must be done to mitigate environmental impacts. 


\subsection{Needs Assessment}

Conducting a needs assessment study constitutes the primary requirements of transportation improvements. A needs assessment study involves an assessment of future transportation problems, opportunities and transportation options within a broad analysis area. To conduct a needs assessment study represents the first phase of MTO process to initiate the environmental assessment process for new transportation corridors. When the existing transportation network is not capable of supporting the projected growth in population, employment, trade and tourism, it needs to be extended.

For the MPTC the needs assessment study was a technical study, involving a comprehensive examination of future transportation problems, opportunities and a range of transportation alternatives including road, transit, rail, ferry and other options. Various travel and growth scenarios were considered for a 30-year planning period. The needs assessment study concluded that significant additional transportation capacity would be required through the Niagara Peninsula into the GTA to accommodate future growth in the movement of people and goods. The needs for significant improvements to the transportation network are driven by several factors including population growth (and associated employment growth), trade growth, tourism growth, land use policies, and growing congestion in the existing transportation system. The needs assessment study proposed a broad multi-modal "Transportation Development Strategy" to ensure adequate transportation network operations over the long term. The MPTC needs assessment was carried out by MTO as a separate planning and decision-making process in accordance with the following description contained in the class environmental assessment (MPTC needs assessment study, 2003).

- To identify transportation problems and opportunities.

- To evaluate and select reasonable "alternatives to".

- To develop provincial transportation facility study objectives - "the purpose of the undertaking".

- To accommodate future growth in the movement of people and goods.

- To improve the international trade through the corridor.

- To improve tourism and travel.

- To improve accessibility for tourism, industry and commerce. 
- To support economic growth at the provincial and municipal levels.

- To reduce traffic congestion and delay, accidents, fuel consumption and emissions on existing area road network.

- To defer rehabilitation requirements on existing local highways/roadways.

- To optimize use of existing rights-of-way/facilities.

- To reduce travel demand and optimize existing infrastructure through use of innovation/technologies such as Transportation Demand Management (TDM) and Transportation System Management (TSM).

- To planning for existing and new transportation corridors to minimize impacts associated with adjacent highway development.

- To pertaining population and employment growth, trade growth, tourism growth, land use policies and projected traffic congestion in relation to the need for the corridor.

\subsection{Environmental Impact Assessment (EIA)}

EIA is defined as the systematic identification and evaluation of the potential impacts (effects) of proposed projects, plans, programs or legislative actions relative to the physical, chemical, biological, cultural and socio-economic components of the environment (Canter, 1996). As a planning tool, environmental assessment is used to identify and ensure that the potential environmental effects of projects receive careful consideration before they are undertaken. Failure to consider the adverse environmental effects of projects can lead to environmental degradation, damages to human health, and increased economic cost. Environmental assessment is a critical tool for sustainable development given the potential for irreversible damages to the environment that can result from human activities. It provides decision makers with the means to obtain the information they need to make balanced and informed decisions to sustain a healthy environment and strong economy for present and future generations.

Nowadays, the EIA is needed to ensure the protection of the environment and the natural resources from any unexpected side effects, which may be occurred during the process of the projects. Simply, EIA is a study of the effects of a proposed action on the environment, where the term environment includes all aspects of the natural and human effect (El-Raey, 2003).

In Canada, converging social, economic and environmental agendas are becoming increasingly evident. Canadians can design better projects and policies that balance and 
integrate society's environmental goals with its economic goals, social goals and cultural values.

Sustainable development is a fundamental aspect of the environmental assessment process. Best-practice EIA identifies environmental risks, lessens conflicts by promoting community participation, minimizes adverse environmental effects, informs decision-makers, and helps lay the base for environmentally-sound projects. As a planning and decision-making tool, the Canadian Environmental Assessment Act has helped to achieve sustainable development through the promotion of sound economic development that conserves and enhances environmental quality.

The transport policy established by the government has put more weight on environmentally friendly operations of the road transport sector. Over the past number of years, the Ministry of Transportation, Ontario (MTO) has undertaken a significant amount of technical, forecasting and strategic planning work in the Niagara, Hamilton and Halton areas. MTO has commenced the formal environmental assessment process for the Niagara to GTA corridor for the environmentally friendly operations of the road transport sector. It should contribute to preservation, protection and improvement of the environment, protection of public health, and the conservation of natural resources. In order to reach these requirements environmental impact assessment in the process of road planning has to be integrated.

History of EIA

During the decade of the 1960 's, the growing concern for environmental quality put considerable pressure on the planning process and its ability to adapt to change (Looijen, 2000). The originated year of EIA practice in some develop countries are given below.

- EIA was first introduced in the USA.

- Canada followed in 1974.

- China started in 1980. The EIA law of China was promulgated in 2002 which provides that EIA is required in regional and sector plans and programs.

- Netherlands in 1987.

- European Commission in 1988 introduced a set of guideline on EIA dictating member countries to incorporate the guidelines in national legislation. 


\section{Objective of EIA}

Environmental assessment should be conducted as early as possible in the planning and proposal stages of a project for the analysis to be valuable to decision makers and to incorporate the mitigative measures into the proposed plans. Timely and efficient environmental assessments result in more informed decisions-making that support sustainable developments. The environmental impact assessment should have the following objectives.

- Apply to all projects that are expected to have a significant environmental impact and predict environmental impact of projects,

- Compare alternatives to a proposed project and find ways and means to reduce adverse impacts,

- Shape project to suit local environment, and

- Monitor and feedback procedures.

\section{Principles and Characteristics of EIA}

The engineering project may have negative effect on the environment. Therefore, the effect of any project on the existing physical environmental should be predicted with degree of reliability and high accuracy. EIA provide decision-makers with analysis of the total environment so that decisions can be made based on as nearly complete and balanced information as possible.

Based on the scale and significance of potential impacts, EIA can be determined by four principles and eight main characteristics. These principles are summarized as Participation, Transparency, Certainty, Accountability, Credibility, Cost effectiveness, Flexibility and Practicality. The characteristics are magnitude (extension of impact-measurable quantity), importance or significance (social value), higher order and cumulative effects, reversibility and irreversibility, duration, remedial measures and risks and uncertainty of occurrence (Gramangis, 1981). 


\section{Main Steps of EIA}

Many important steps help to identify possible environmental effects and mitigative measures. The process of EIA varies with laws and local practices prevalent in each country. Generic steps and public participation that should be included in each (Smith and Wansem, 1995) are discussed below. It is imperative to understand the interlinkages and dynamics between various activities and direct, indirect, and cumulative impacts on physical and social environments to evaluate the impacts and to provide mitigation measures. The key steps in preparing the environmental assessment include:

- Identifying significant study area features.

- Identifying route alternatives.

- Refining route alternatives.

- Assessing potential environmental effects.

- Evaluating route alternatives and selecting a preferred route alternative.

- Examining concept design alternatives and selecting the preferred concept.

- Developing mitigation measures.

- Consulting with regulatory agencies, municipalities, and the public (including potentially affected property owners and interest groups).

\section{EIA Process}

As a decision-making tool, EIA is heavily influenced by the nature and structure of the local planning process. But in spite of the differences in the planning process, the EIA process can be generalized and divided into following stages:

a) Screening- A screening is a systematic approach to document the environmental effects of a proposed project and determine the need to eliminate or minimize (mitigate) the adverse effects, to modify the project plan, or to recommend further assessment through mediation or an assessment by a review panel. The responsible authority must ensure that the screening of the project is carried out. In the screening stage, the EIA agency consults the proponent, other agencies and public participants to determine the requirements of further studies. At this stage, the EIA agency determines whether the project may proceed as planned or if it needs to be subjected to an initial or complete EIA. 
Screenings will vary in time, length and depth of analysis, depending on the circumstances of the proposed project, the existing environment, and the likely environmental effects. Some screenings may require only a brief analysis of the available information and a brief report; others may need new background studies and will be more thorough and rigorous.

b) Comprehensive study- The majority of federal projects is assessed through a screening; however, some projects require a comprehensive study. These tend to be large projects having the potential for significant adverse environmental effects. They may also generate public concerns. Early in the comprehensive study, the Minister of the Environment has to decide whether the project should continue to be assessed as a comprehensive study, or whether it should be referred to a mediator or review panel

c) Scoping- Determining the scope of environmental issues to be scrutinized in the EIA and defining the scope for each issue. The scoping stage, often merged with screening, deals with a more detailed plan of study for the project to identify major concerns and key impacts, and to decide assessment methods and models to be used. Agencies and public representatives concerned with the project or the project area are consulted.

d) Impact assessment - Assessment of each topic selected in the scoping stage. This step takes up most of the EIA time and resources. For each topic, the current status is delineated, and the predicted impacts are forecast by means of models. In the cases where adverse impacts are identified, mitigation measures are proposed.

e) EIA preparation - At the end of the impact evaluation, a document EIA is prepared. This document is passed on to the competent authority. Usually, after the authority makes its decision on the proposed project, the public can inspect the EIA and in many countries can resort to the courts. Hence, the EIA is a legal document.

f) Alternative evaluation criteria- It will generally include a mixture of legally-mandated criteria, technical/scientific criteria and social acceptability criteria. Alternate sites and design process should be critically examined to maximize the positive environmental impacts, socioeconomic benefits, and profitability, and minimize the temporary adverse impacts. 
g) Post project analysis (PPA) - In some countries, the environmental authorities continue to follow the proposed project in order to check that the project initiator is following the orders of the competent authority and also to improve the EIA system as an ongoing process.

An overall framework of EIA process for planning and conducting environmental study is shown in a flow chart in Figure 1.

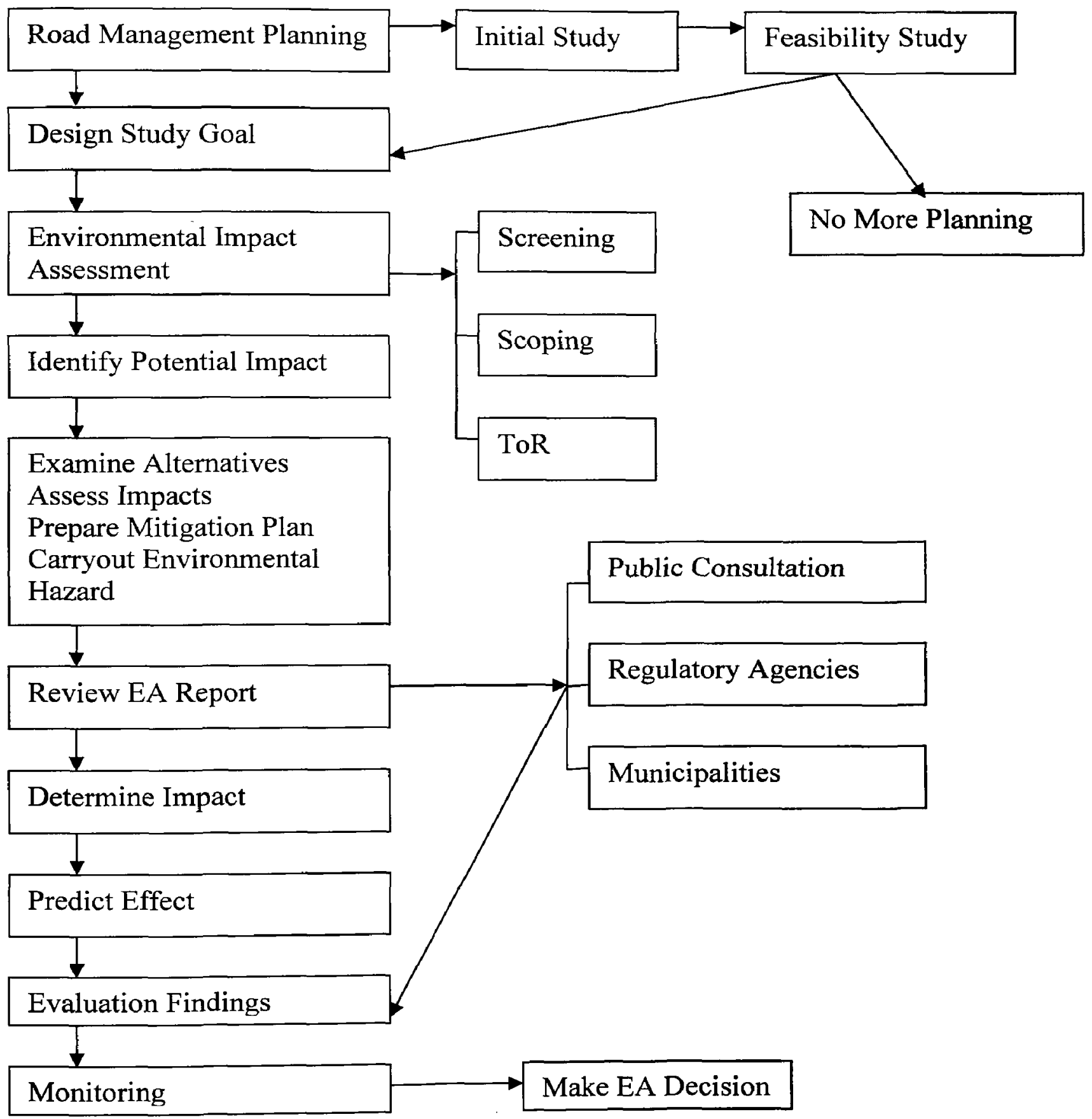

Figure 1 Schema for the process of environmental impact assessment. 


\section{The Main Actors in EIA}

Several stakeholders are involved in the EIA process and this may very according to country and institutional framework (Looijen, 2000). The first actor is the proponent that proposes an activity, policy, plan program or project. The main actors in the EIA process is shown in Figure 2 and described below.

Decision makers-A decision-maker is the body or person responsible for deciding on the proposed project, whether a project shall proceed or not, or proceed subject to condition and constraints (Gilpin, 1995). In order to identify the decision-maker in EIA there should be a clear identification of the responsibilities and organizational structure of the particular agency involved in an EIA and a clear determination where decision for the type and scale of project under consideration are made (Kreske, 1996). It is thought that the decision-maker concerning the EIA differs according to the proposals size, its objective, and the country institutional structure.

The public and NGOs -Every person can participate in giving his/her opinion on the guidelines and EIA. It is thought that public participation differs greatly from one place to another place, when a corridor is proposed for connecting remote place to greater area, makes the congestion at connecting area, so naturally public opinion differs of these places. The public participation is when the project had been proposed and it should continue upto and during the construction and operation period.

Consultation group-A team of specialists was assembled from various disciplines as natural sciences, socio-economics, acoustics, vibration, air quality, archaeology, heritage, waste/contamination, drainage, stormwater management and geotechnical. They are working in technical and environmental research units and carrying out the actual environmental impact study including producing an environmental impact study and preparing a report of the assessment for the decision makers. 


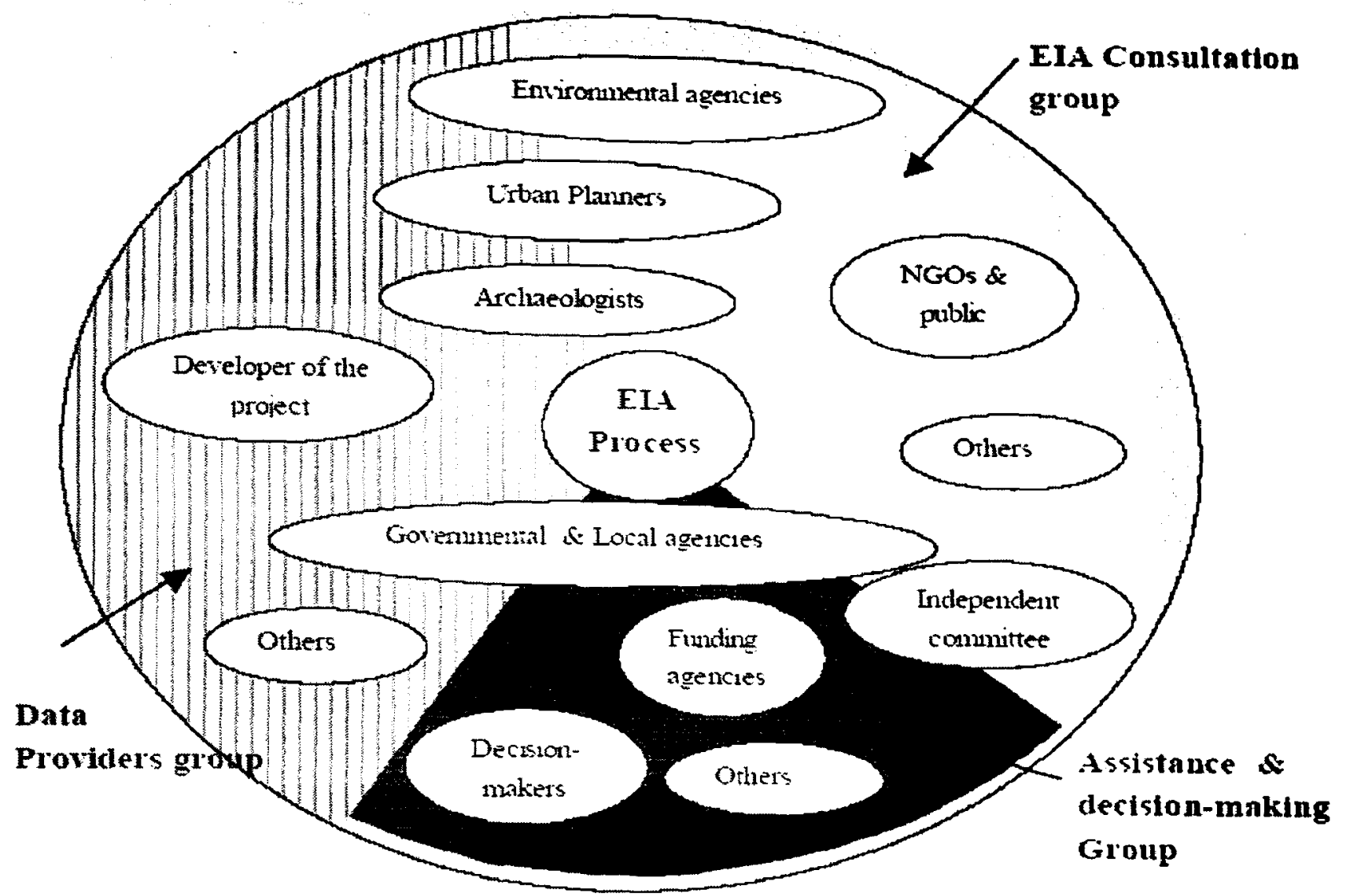

Figure 2 The main actors in EIA process.

(Source: [Ghaffar K. S., 2001])

\section{Benefits of Environmental Assessment}

By considering environmental effects and mitigation early in the project planning cycle, environmental assessment can have many benefits, such as:

- An opportunity for public participation,

- Increased protection of human health,

- The sustainable use of natural resources,

- Reduced project costs and delays,

- Minimized risks of environmental disasters,

- Increased government accountability, and

- Overall it minimizes or avoids adverse environmental effects before they occur. 


\subsection{The Potential Environmental Effects for MPTC}

It is difficult to comment on the specific environmental impacts associated with a MPTC at the Terms of Reference stage, as a preferred route location alternative has not been selected. A team of specialists was assembled from various disciplines as natural sciences, socioeconomics, acoustics, vibration, air quality, archaeology, heritage, waste/contamination, drainage, stormwater management and geotechnical to aid in the preparation of this EA Terms of Reference. These specialists were instrumental in the preparation of documentation, the administration of the study process, the research and consideration of secondary source information, and the consultation with government agencies. However, the specialists from the disciplines noted above have a good understanding of the existing environmental conditions (based on their experience and secondary source research) and the further study required to generate route alternatives, assess the impacts of route alternatives and complete the evaluation that will lead to a preferred route. The work plans outline objectives for generating routes to minimize adverse environmental impacts, describe how impacts associated with route alternatives will be assessed, and outline the specific studies and field work that will be undertaken to assess impacts and develop mitigation measures. This understanding is clearly documented in a series of environmental and technical work plans and given below.

\section{Natural Environment}

- Minimize the number of water crossings.

- Minimize impacts to water bodies including channel realignments and fill.

- Avoid wherever possible critical fish habitat features (spawning, rearing, nursery, important feeding areas.

- Avoid where possible or minimize potential impact to species at risk (vegetation, fish and wildlife.

- Minimize encroachment into ecologically functional areas such as connective corridors or travel ways.

- Minimize intrusion into identified important wildlife areas such as deeryards, heronries, waterfowl areas, important bird areas. Other areas to be considered are any identified wildlife management, rehabilitation and research program sites. 
- Avoid encroachment on provincially significant wetlands.

- Avoid where possible or minimize encroachment on significant forest stands and woodlots.

- Avoid where possible or minimize encroachment on existing mapped Carolinian Canada sites as well as elements of the Carolinian Canada "Big Picture", Natural Heritage System of core areas, other significant areas, and potential corridor.

- Avoid where possible or minimize the encroachment onto known groundwater recharge and discharge areas; as well as identified wellhead and source protection areas and areas susceptible to groundwater contamination.

- Avoid or minimize encroachment on environmentally significant features such as significant valley lands, environmentally sensitive areas, areas of natural and scientific interest (ANSIs) or other areas of provincial, regional or local significance.

- Avoid impairment of function of these features to the extent possible

- Maximize separation distance between the route alternative and sensitive receptor locations.

- Minimize encroachment near existing and proposed urban and rural residential developments.

- Follow a direct route to minimize green house effects.

Socio-Economic Environment

- Minimize the number of developed properties affected by the right-of-way requirements by following existing lot lines and concession lines to the extent possible.

- Minimize disruption of access.

- Minimize potential impact of reduced access by avoiding urban areas, hamlets and rural cluster.

- Avoid where possible or minimize encroachment on prime agricultural areas and agricultural infrastructure.

- Avoid where possible or minimize encroachment on mineral, petroleum and mineral aggregate resources. 
- In urban areas, avoid where possible or minimize encroachment into commercial/industrial areas.

- In rural areas, avoid retail/commercial areas such as service stations and isolated industrial areas such as manufacturing plants.

- Maximize separation distance between the route alternative and sensitive receptor locations.

- Minimize encroachment near existing and proposed urban and rural residential developments.

\section{Cultural Environment}

- Avoid archaeological sites of extreme significance.

- Minimize the number of built heritage features displaced (loss or relocation) in the study area.

- Minimize the number of cultural landscape units displaced (loss or relocation) in the study area.

\section{Technical Considerations}

- To generate route alternatives that meets design requirements.

- To generate route alternatives that is efficient and direct.

\subsection{EIA and Road Planning}

Road projects occur over long distances that typically cross through a number of different environmental conditions. Identification and avoidance of environmental impacts is principally achieved through the constraints and route selection stages. Road planning and design is an iterative process where the planning and design evolve in response to environmental and other considerations. This ensures that environmental considerations become an integral part of the overall route corridor selection and road scheme planning and design process.

The very important things at early stages of planning is selection of alternative routes and establish the criteria for comparing and choosing between alternatives and choice of the preferred route. The avoidance of impacts through the early consideration of alternatives may 
be the most important and effective environmental mitigation strategy. Introduced at an early stage of the planning process, EIA provides the knowledge about the risk to the environment from planning facility, and its operation is obtained adequately and continuously. By describing the impacts of the various alternatives and comparing them with a "do nothing alternative" (the situation when the project is not implemented), it is possible to make the choice of the final road corridor and later, final road profile more objective. This also means that the solutions can be designed in such ways that negative impacts are limited and positive. It might be relevant to underline that EIA comprises not only environmental/ecological impacts but equally covers social and national economic impacts.

\subsection{EIA at Different Stages of Road Planning}

EIA can be done at all stages of road planning. Depending on the planning stage and the type of decision that is to be made, EIA can have different tasks and focuses on different issues.

\section{EIA at System Level}

At the system level EIA provides an impact assessment for the entire road and transport system and concentrates on impacts that are important in achievement of long-term environmental goals. It evaluates how the project and proposed road measures correspond with national and regional environmental goals and takes up questions that are of importance to the environmental adaptation of the entire road transport system, including coordination with other types of transport (Vägverket, 1995). Finally, EIA makes an overall assessment of the whole project and contribute to the decision weather or not the project is feasible from the environmental point of view. At this stage it is being determined which direction is to be taken in the EIA work, which types of impacts should be included, and which aspects in EIA should get the first and the second priority. Among other aspects, EIA gives an overall assessment of the following consequences:

- Communication interests come into conflict with other public interests,

- What impacts (for example, water and air pollution and deterioration of living condition) are expected for those who live in the area affected by the road planning, risk of creating conflict with strong preservation and recreation interests, and

- The effect on the land-use structure and land-use planning. 


\section{EIA at Project Level}

At the project level, EIA provides input data for the decisions on where a possible new corridor can be located, how sections of the road should be designed with a minimum impact on the environment and which environmental measures have to be taken. EIA is included in all stages of road planning at this level.

In the initial study the role of EIA is to give a general assessment of what the potential impacts from alternative solutions are and to assist in selecting those solutions that will be submitted for consideration in the next stage. EIA is also needed to define the possibilities and limitations of the project regarding its environmental adaptation, so it would be possible to set up the priorities and specify which environmental aspects are of most importance. EIA makes an evaluation on how the project from environmental point of view concurs with the direction and the goals of the strategic planning. At the same time EIA work in further stages gets scopes and direction. In the feasibility study EIA contributes to the comparison of alternative corridors and serves as a basis for weighing up which alternative should later be a subject of detailed design (Vägverket, 1995). The comparison is made on the basis of information about impacts from different alternatives with technical and economic evaluation of protection measures that are needed in each case. EIA is also important when considering the public interests in decision-making. During the generation and evaluation of alternatives, various routes will have common points where routes intersect. In such cases, an analysis will be undertaken to determine preferred routes for portions of the study area rather than comprehensively examining all combinations of routes for the entire corridor. For example, alternatives between common points " $A$ " and " $B$ " would be compared to select a preferred alternative route for that segment of the corridor prior to assessing alternatives beyond common point "B" (see Figure 3). 


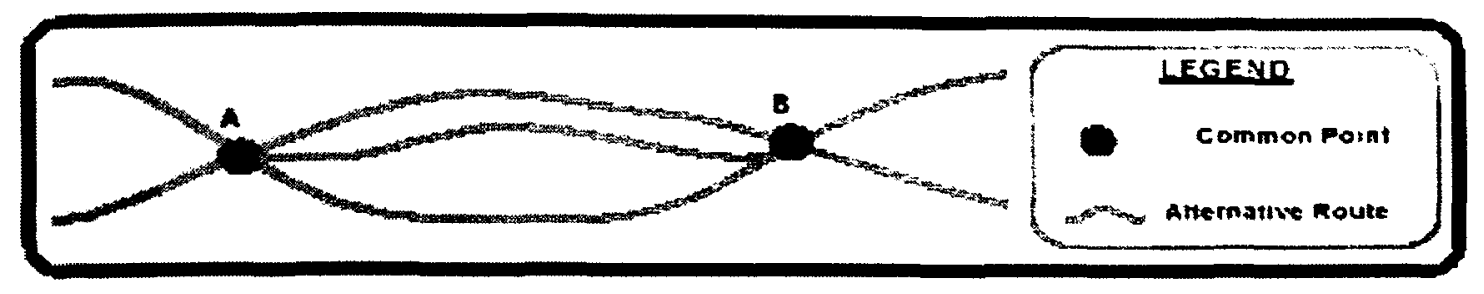

Figure3 Common point analysis.

[Source: (Niagara to GTA Corridor Need Assessment ToR, 2003)]

In the road design, EIA is necessary while making the choice of the road profile. It provides a detailed study of the impact assessment from construction and operation of the finally chosen road profile and indicates the needs for the environmental adaptation and protection measures. 


\section{USE OF GIS FOR EIA}

\subsection{Introduction}

A Geographical Information System is a computer-based tool for handling spatial data and can play a vital role for analysis and in formulating the quick mitigation plans for high risk environments. GIS is a powerful tool for environmental data analysis and planning. GIS stores spatial information and data, which can be overlaid with data or other layers of information into a map in order to view spatial information and relationships. GIS allows better viewing and understanding of physical features and the relationships that influence in a given critical environmental condition. It can serve as the ultimate communication of environmental information to the public and policy makers since it is the technical basis for the multimedia approach in environmental decision-making. The evolution of spatial data standards, the Internet and the next generation of GIS technology allow all types of users to access the environmental information in its proper spatial context.

In recent years two important developments have helped in reducing the complexity of spatial analysis. In the last decade, due to the evolution of computer technology, and especially their graphic capabilities. In addition the availability and quality of digital spatial data sets have improved, to the level where they are now adequate for routine analysis (Batty, 1993). Both governmental and non-governmental institutions are adopting GIS technology as spatial data become more widely available. Many sources of data are now available on the World Wide Web for little or no cost. In addition, while GIS still requires some special training, the technology is becoming considerably more user-friendly. For example, Internet Mapping Servers (IMS) offer a way to provide mapping capabilities to the public in a way that involves little or no training and does not require each user to own expensive GIS software. As a result of these innovations to make GIS more user-friendly and accessible, increasing numbers of institutions are developing their own spatial data and GIS applications tailored to meet local needs. GIS has a capacity to provide a very flexible system for gathering data from many sources in a variety of formats. Moreover, it has a capability to transform analog data into digital form. GIS can easily integrate in one system several data types, such as maps, images, digital products, Global Positioning System (GPS) data, text and tabular data. These and other 
types of data are combined and integrated into GIS in the form of a database, a program or system that provides an effective storage and management of data. Database allows to keep track of data and to hold it conveniently for use (Devis, 1996). While working with data a lot of technical problems can appear, for example: to be able to use geographical data in different scales, or to set geographical boundaries for the area of study, or to adjust data to a particular task.

On completion of data analysis GIS helps in planning and managing the environmental hazards and risks. In order to plan and monitor the environmental problems, the assessment of hazards and risks becomes the foundation for planning decisions and for mitigation activities. GIS supports activities in EIA monitoring and mitigation and can also be used for generating environmental models.

EIA is becoming more and more extensively used in the world. EIA is an aid system to decision-making and to the minimization or elimination of environmental impacts at an early planning stage. The EIA process is potentially a basis for negotiations between the developer, public interest groups and the planning regulator. Therefore, an EIA has to be started before project initiation. EIA is a management tool for officials and managers who make important decisions about major development projects (Hossein, 2004).

As a rule, EIA is applied for physical objects or facilities that can be located on the ground and hence, can be described by geographical coordinates. In order to perform EIA a lot of information about the studying objects and facilities should be collected and analysed. Most of such information has geographical references, i.e., can be connected to a certain point (object, facility) on the ground. The need to process a lot of spatial data and information quickly and effectively makes the adoption of GIS for the needs of EIA almost inevitable. Accepting GIS as a means of using spatial data can have many advantages over traditional methods while making use of spatial data.

Spatial data used in EIA is coming from different sources, in different forms (both digital and analog) and in different formats (i.e., digital). This creates problems when working with a large amount of data, especially when it should be integrated or compared. Another problem is storage of data; since there are a lot of people working with the same data, it should be well organized, quickly accessible and easy to exchange. Besides this, more and more digital data 
are being used, which creates a need of a computer system that can accept, convert and manage large amounts of digital data.

GIS technology offers many tools for manipulating spatial data; among others is a possibility to store data in different thematic layers, which gives a user the power to combine different information layers according to the EIA need. When operating with GIS functions the user can very easy define the locations of spatial features and make measurements of different types of spatial parameters, such as distance, perimeter, area and size. GIS allows making use of data more efficiently by offering possibilities to manipulate data to produce new information.

Among various tasks of EIA is to be able to give forecasts of possible consequences that the project can have on the environment. In this case, GIS can provide its user with numerous tools for analyzing geographical data and revealing trends and patterns when making different scenarios. When the results of EIA are presented for public and authorities, they should be in short but informative form instead of bulky reports. GIS technology gives good outcomes when used to visualize information. Possibility to display information in form of maps in combination with graphs, tables and texts has proved to be the most efficient way to present geographical information.

\subsection{The Integration of GIS into EIA}

EIA is decision processes, which aims to both identify and anticipate impacts on the natural environment. The interface between these two components produces several effects, which will generate specific impacts. The environmental systems include spatial data relevant to the decisions, analytic tools to process the data in ways meaningful for decision makers, and out put or display functions. An EIA can be defined as the evaluation of the effects likely to arise from a major project, or other action, significantly affecting the natural and man-made environment (Wood, 2003). One of the shortcomings of the EIA process is that it lacks a spatial dimension which is important in determining impacts accurately (Antunes, et al., 2001). Another gap in knowledge is that in the past there have been very few projects which incorporated ecological, social and engineering variables. For example, a study by Antunes et al., examined ecological variables involved in sighting a highway, but failed to incorporate social and engineering variables. In another study by Sadek, et al. (2000) integrated 
ecological and engineering principles into their highway analysis; however their analysis still lacked social variables. With the integration of GIS into the impact assessment process, problems such as the lack of a spatial dimension will be removed from the process. The ability to integrate information and support decision-making is the true power of a GIS. Petch (1993) explained on geography in decision-making that there are certain management decisions for which spatial information, analysis and cognition are essential and that the use of maps influences how we look at or conceive things and therefore what we decide. Although subjectivity will never be completely removed from this process, the use of GIS will make the impact assessment process much more objective (Antunes, et al., 2001). This is only true if the correct variables are used and weighted accordingly. The other significant uses of GIS in impact assessment are namely for data management, overlay and analysis, trend analysis, as sources of data sets for mathematical impact models, habitat and aesthetic analysis, and public consultation (Antunes, et al., 2001). GIS has also been combined with other specialized systems in order to determine environmental impacts such as air pollution. For example, air pollution is a complex problem as air flow modeling must also be combined into the GIS. Most standard GIS systems are not capable of calculating this air pollution factor and specialized GIS systems must be designed (Rebolj and Sturm, 1999).

In 1972 a computerized version of the technique was used for power lines and roads (Munn, 1975). It is noteworthy that the so called "first GIS" (Canada GIS) was used for EIA in the late 1970's for the preparation of environmental impact studies for a dam on the river Thames. GIS offers a special environment for dealing with the spatial properties of a project. Those special attributes of the GIS are very important for the analysis of environmental issues, since most of them are spatial by nature, and no other computerised system can handle them properly (Schaller, 1990). However, the use of GIS in EIA process in general, and for scoping in particular has been limited, due in part to their cost in terms of time and money relative to the time and budgets allocated for EIA preparation, and especially for scoping. GIS will bring to the EIA process a new way of analyzing and manipulating spatial objects and an improved way of communicating the results of the analysis, which can be of great importance to the public participation process. GIS represent the most suitable way to deal, represent and analyze these data sets. Figure 4 show that how GIS can be employed within the 
EIA process to improve different features, mainly related to data storage and access, to the analytical capabilities and to the communicability of the results to decision makers.

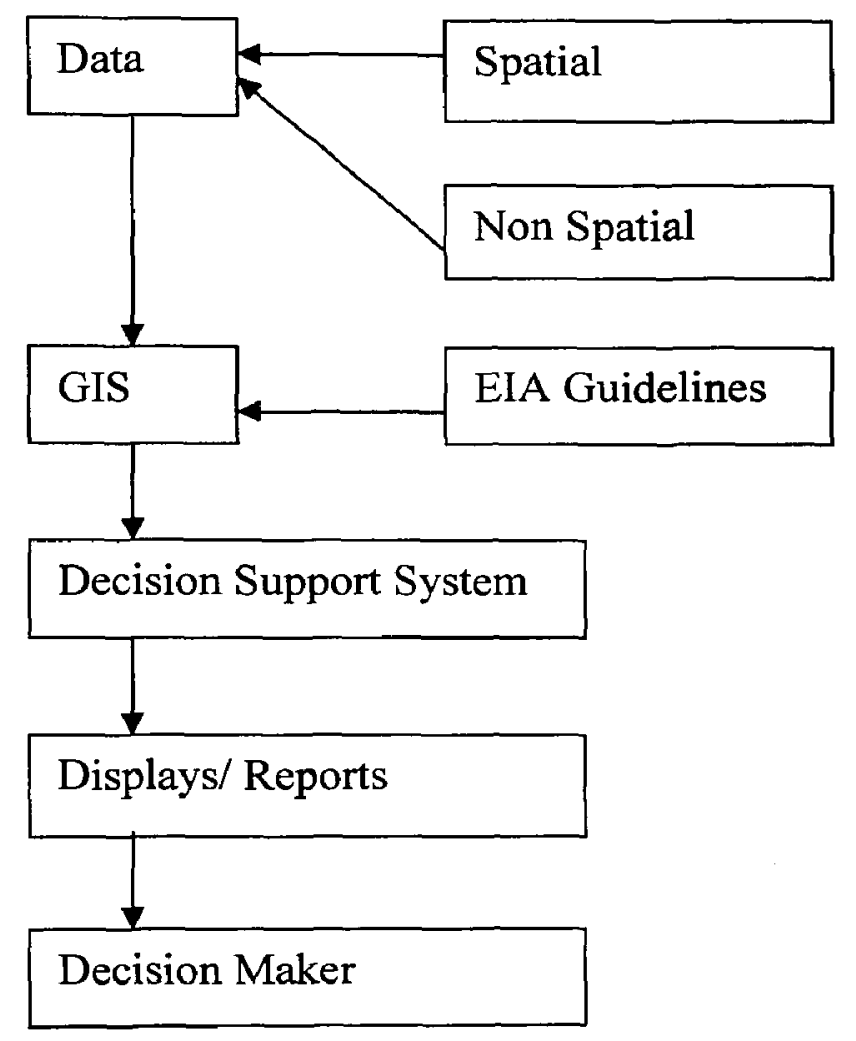

Figure 4 GIS in the EIA process

Geographical information systems can be applied at all EIA stages. This utilization does not make use of the key advantage of GIS for EIA, its ability to perform spatial analysis and modeling (Joao and Fonseca, 1996). The development of such a system will allow a more realistic approach to the environmental descriptors and a better understanding of their interrelationships. Erickson (1994) identified four methodologies associated with impact assessment, each with its own strengths and weaknesses. As such, it might be useless searching for an ideal technique. A more realistic approach is to identify the relative merits of 
these alternatives. This way, a combination of techniques can be chosen to meet the needs of a particular problem. The four methodologies are:
1) Overlay
2) Checklist
3) Matrix
4) Network

The overlay method of impact assessment requires physical or computerized overlays of individual maps of social and physical attributes of the project area. The data it uses include topological data, air dispersal patterns, land and resource use data, wildlife, surface and ground water intakes. Such data may be obtained from aerial photography and satellite remote sensing. This method thrives on graphical display of data, but it is limited in that it lacks analytical capabilities. GIS is the ultimate tool for overlay the environmental data.

The checklist method can be a very simple or complex list of environmental components, attributes and processes, which are categorized under disciplinary headings such as geology, vegetation and air. GIS provides a computer platform for organizing, storing and analyzing these checklists.

The matrix method, which is a modification of checklist, facilitates related specific project activities to specific types of impacts. Matrices are found necessary because they emphasize only direct impacts. It forces consideration of impact of each aspect of a proposal for a range of environmental concerns and it considers both the magnitude and importance of impacts. Again, GIS provides a powerful tool for organizing, analyzing and storing matrices.

Lastly, the network methodology defines a network of possible impacts that may be triggered by project activities and that require the analyst to trace out project actions and direct and indirect consequences. Using the network method, direct, secondary, and tertiary and other higher order impacts of action may be well traced out. This method cuts across disciplinary lines and it forces the identification of site-specific factors and conditions necessary for the establishment of a proposed cause-effect relationship. This technique however requires that the analyst be knowledgeable in the various types of environmental components and dynamics. On a GIS platform, the analyst is further aided as large volumes of data can be better analyzed in a short while. 
GIS is an excellent tool to assist decision-makers, but also the public in (spatial) planning (visual illustration of environmental data interpretation). During the planning of a particular development, several technological, economical and environmental criteria must be fulfilled before the physical work can begin. In this process spatial analysis with the help of a GIS is a huge benefit. When planning to select any location with minimal impact to the environment, the evaluation of alternatives is an integral component of the best location. Weighting scenarios is used for this evaluation component. Generally, more weight is assigned to those features, which are felt to be more important in assessing impacts generated by alternatives, and less weight is given to those features, which are considered to be less important. The totals for each alternative are compared to determine the preferred alternative. Recent surveys of the use of GIS in EIA found that while GIS is widely utilised, its use is largely limited to the basic GIS functions such as map production, classic overlay or buffering (Joao, 1996), the overlay analysis is made much more powerful through the use of GIS (Smith, 1993). Antunes, et al., (1996) used GIS as integrating framework for impact prediction and evaluation for decision support. The case study of this report presented a GIS based map overlay method to analyze and present the impacts due to MPTC on the surrounding environment.

\section{GIS applications in EIA}

In EIA many environmental factors are of spatial in nature, so Geographic Information System can have a wide used in all EIA stages which include (Rodriguez-Bachiller, 1995):

- Terrain use for slope and drainage analysis.

- Land-resource information systems for land management.

- Soil information for soil studies.

- Geoscientific modelling of geological formations.

- Disaster planning related to geographically localized catastrophes.

- Analysis of irrigation suitability.

- Contamination and pollution monitoring.

- Flood studies.

- Determine preferred alternative route.

- Linking environmental databases.

- Constructing global databases for environmental modelling. 


\subsection{Overview of Cases}

This section is providing an overview of the development of GIS applications in world. The cases below present information on the challenges and solution of the environmental problems.

Since the early 1990s, the Arkansas Highway and Transportation Department (AHTD) has been developing GIS applications to support the analysis of alternative project alignments, with a growing degree of internal staff and consultant expertise and comfort with the technology. Through this incremental growth, AHTD recognized that GIS could help determine project impacts for EISs in a more efficient manner. In AHTD's view, the technology could provide a quick, accurate, and precise instrument for the generation of maps detailing the environmental constraints for multiple alternative alignments for a proposed project. AHTD's GIS on the I-69 SE-Connector was to foster early coordination with resource agencies, the public and Native American tribes while efficiently addressing the requirements of the environmental review process. AHTD delineated two-mile wide preferred corridors, each with 300 -foot alignments. GIS coverages containing environmental constraint data were overlaid on each of the preferred corridors, allowing for quick and thorough identification of draft EIS alternatives. The GIS-generated maps and analyses provided partnering agencies and communities tangible examples of how various project alternatives would impact environmental, cultural, and economic resources. Partnering agencies supported GIS use because project steps occurred more quickly. The public especially welcomed the GIS and appreciated the map visualizations. AHTD noted that public participants were eager to learn how the project would affect their neighborhoods, properties, and houses. By providing this information, AHTD was able to garner quick public response on the subtle differences of proposed alternatives.

Since 1996, the Minnesota Department of Transportation (Mn/DOT) has been developing an archaeological predictive model, $\mathrm{Mn} / \mathrm{Model}$ (see Figure 5), to avoid impacts to archaeological sites throughout Minnesota. An archaeological predictive model is a tool that indicates the probability of encountering an archaeological site anywhere within a given area. Using these models, construction projects can be modified to avoid areas where archaeological sites are likely to be present. The goal of $\mathrm{Mn} / \mathrm{Model}$ is to be accurate enough to predict 85 percent of 
known archaeological sites without designating more than 33 percent of the State's area as high or medium site probability. MnDOT used GIS and statistical analysis to produce the current archaeological predictive model so that it could be replicated by anyone using the same data and following the same procedures.

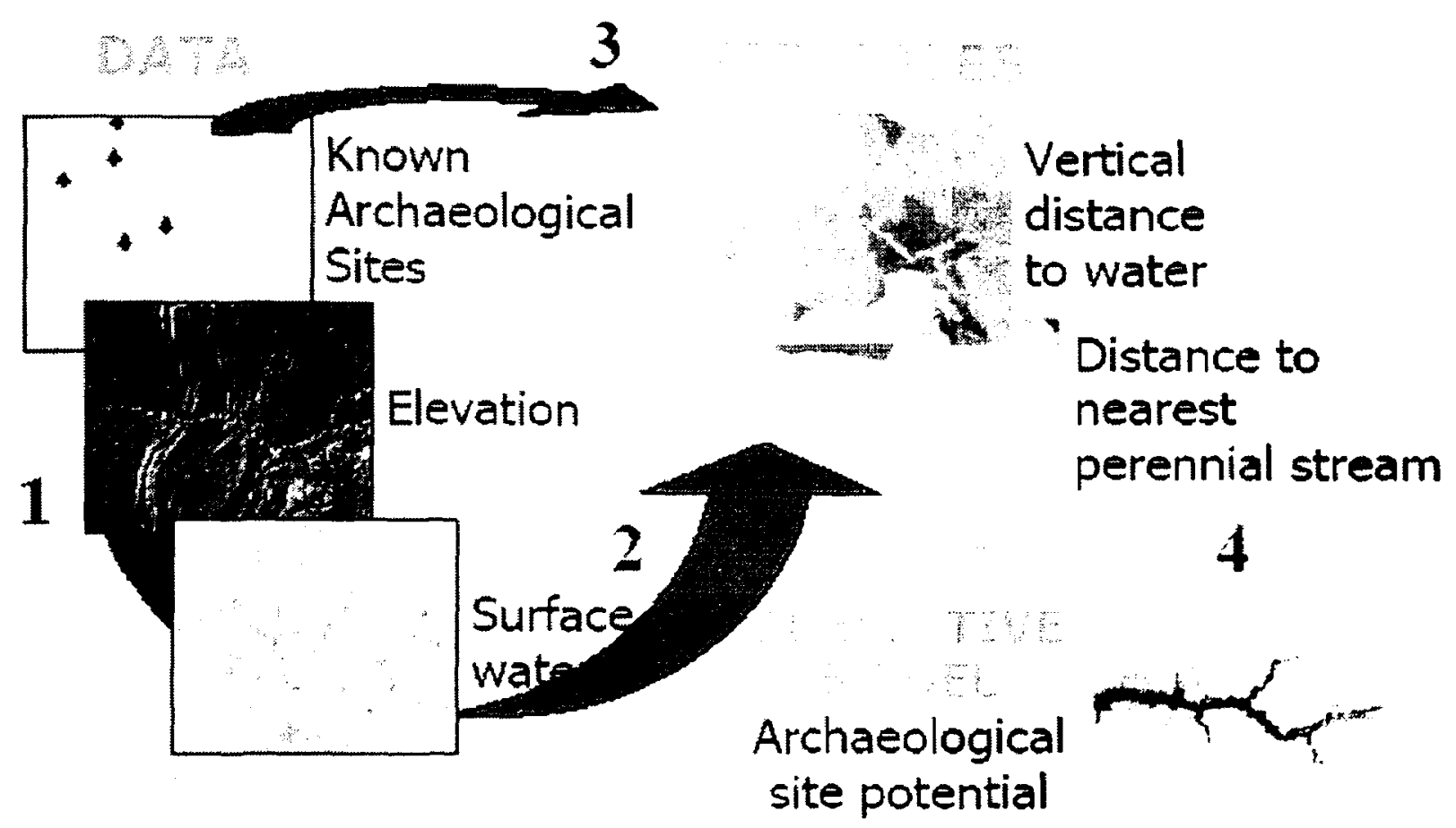

Figure 5 Archaeological predictive model.

[Source: (Minnesota Department of Transportation, 2001)]

The project, entitled "GIS-Based Cumulative Effects Assessment" (Study No: 34.65) has been conducted by the University of Colorado Geographic Information Systems Programs, faculty and staff over a 2-year period, from April 2002 through March 2004. The report describes the development and application of geographic information systems (GIS) and remote sensing (RS) databases and analysis models for cumulative effects assessment resulting from growth associated with transportation infrastructure. A spatial environmental database was collected from various sources for a $53 \mathrm{~km}$ by $97 \mathrm{~km}$ (33 mi. by $60 \mathrm{mi}$.) region bounding I-25 from Denver to near the Colorado-Wyoming border. This report demonstrates several ways that GIS can be used as a tool for performing Cumulative Effects Assessments (CEA). It presents 
four environmental assessments which use GIS. The first two, a habitat suitability study and a land use change analysis, demonstrate commonly used GIS overlay and distance techniques; the remaining two use less common and more complex technologies. The third study links a spatial database with commonly used flood design procedures to measure hydrologic impacts due to land use change. The final study uses a number of techniques for growth modeling.

The project, entitled "Remote Sensing Applications for Environmental Analysis in Transportation Planning: Application to the Washington State I-405 Corridor at Oakridge" by Xiong, D., et. al (2002) create maps of overlays of land use and land cover (LULC), transportation networks and population distributions and generate statistics that serve as indicators of environmental impact for the proposed road infrastructure.

The report, entitled "Application of GIS in the Environmental Impact Assessment of Sabalan Geothermal Field, NW-Iran" by Hossein (2004) presented EIA for a geothermal project on the western plains of Sabalan, in the province of Ardabil in Northwest Iran. The study area is a catchment of Khiav River and its area is about $132 \mathrm{~km} 2$. The work carried out of the possible environmental effects of this proposed project as a precursor to an EIA. The main objective was identifying the likely key impacts of geothermal exploration, drilling, and operation, and to suggest potential mitigating measures. Assessment of positive and negative environmental effects of the construction of a geothermal power plant is carried out using a check list and the ArcGIS 9 software.

\subsection{GIS Data}

The data collected on the study area will assist in identifying the types of impacts on each route alternative and each component of the environment. Data include mainly spatial and nonspatial. The spatial data is characterized as point, lines and polygons. Other GIS spatial data are handled as images, or rasters, having simple row and column formats. Attribute data are handled in relational database software comprised of records and fields, and the power of the relational model is applied for these data.

The type of data necessary for an EIA varies with respect to geographical location and nature of the activity. The GIS system contains several themes that are relevant for most EIA studies, such as topography, bathymetry, settlements and population centers, infrastructure, lakes and 
rivers, land cover and use. Information on biological resources such as birds, fish, mammals and invertebrates are included where relevant. Also contaminant data, when available, are often included to give an impression of the state of the environment.

In highway projects where EIA is required for environmental planning and monitoring, there is a need for a practical way to collect the data, and also a need for practical methods of retrieving and storing the gathered information. Finding tools for comparative studies of different types of spatial data is also desirable (Strömquist and Larsson, 1994). In this respect, GIS is a tool that might be well suited. In all environmental issues there is a spatial component and where most EIA is concerned, there is a wide range of data to be handled.

Environmental spatial data include hydrographic data (i.e., rivers, creeks and lakes), vegetation (i.e., orchard, wooded area and tree), wetland, water or air quality and natural hazards such as flooding, landslides, mud slides, rock slides, earthquake faults and liquefaction hazards. Data commonly used to support environmental analysis include transportation systems, cadastral data, political boundaries (i.e., counties, cities, etc.), population, landuse (agricultural, residential and industrial) and other man made structures.

Table 1 of this report outlines the referred data components of the environment (i.e., natural environment, socio-economic environment, cultural environment and technical requirements / considerations) associated with route alternatives. This table also outlines the specific measures and data sources, which will be used to assess impacts. 


\section{Table 1 Components of the environment}

\begin{tabular}{|c|c|}
\hline \multicolumn{2}{|l|}{ Natural Environment } \\
\hline Criteria & Required Data \\
\hline $\begin{array}{l}\text { Effect on groundwater resource areas, } \\
\text { groundwater discharge }\end{array}$ & $\begin{array}{l}\text { Existing information to determine areas of high water table, } \\
\text { areas of groundwater discharge, areas of high groundwater } \\
\text { overburden permeability and location and usage of private } \\
\text { and municipal wells. }\end{array}$ \\
\hline $\begin{array}{l}\text { Surface water quality and quantity, watercourse } \\
\text { crossings, floodplain crossed }\end{array}$ & Topographic maps, base maps, floodplain mapping \\
\hline $\begin{array}{l}\text { Vegetation, forest areas, vegetation } \\
\text { management }\end{array}$ & $\begin{array}{l}\text { Identify vegetation units, base mapping and topographic } \\
\text { mapping }\end{array}$ \\
\hline \multicolumn{2}{|l|}{ Socio-Economic Environment } \\
\hline Criteria & Required Data \\
\hline Noise & $\begin{array}{l}\text { Aerial photographs, municipal land use information, traffic } \\
\text { data }\end{array}$ \\
\hline Support for planned community structure. & Land use mapping \\
\hline Residences/business uses displaced/affected. & Land use surveys, municipal mapping \\
\hline Municipal and regional development goals & Provincial, municipal land use plans, public consultation. \\
\hline Effect on petroleum, mineral resources & Mineral mapping and data on current value of resource \\
\hline $\begin{array}{l}\text { Agriculture, fruit land, cropland, vineyards } \\
\text { affected. }\end{array}$ & $\begin{array}{l}\text { Canada land inventory mapping, public consultation, soils } \\
\text { maps }\end{array}$ \\
\hline Property contamination & Waste generator database, soils and geological maps \\
\hline \multicolumn{2}{|l|}{ Cultural Environment } \\
\hline Criteria & Required Data \\
\hline Disturbance of archaeological features & Archaeological reports, historic mapping, topographic maps \\
\hline $\begin{array}{l}\text { Displacement or disruption of built heritage } \\
\text { features }\end{array}$ & $\begin{array}{l}\text { Historical mapping, municipal, provincial and federal } \\
\text { inventories. }\end{array}$ \\
\hline \multicolumn{2}{|l|}{ Technical Considerations } \\
\hline Criteria & Required Data \\
\hline $\begin{array}{c}\text { Traffic operations } \\
\text {. }\end{array}$ & $\begin{array}{l}\text { Traffic model link volumes, highway plan, profile and cross } \\
\text { section elements, location of existing and proposed transit. }\end{array}$ \\
\hline
\end{tabular}




\subsection{Features and Attributes}

The specification and quantification of a decision criterion depends on physical, environmental and socioeconomic attributes and a geographical location. Physical attributes include features of the built environment, such as airports, cemeteries and archaeological sites. Environmental attributes include not only the location of endangered species, but also their range and habitat. These also include air and water quality indices and ecosystem evaluations. Socioeconomic attributes are modeled in the form of social and community impacts. Travel way attributes include name or identification markers, facility type, signals, geometry, capacity, restrictions, traffic volumes, deterioration conditions, construction/maintenance activities and material characteristics. Watershed attributes include rivers, lakes, channelized rivers, canals, harbors, bridges Name/ID, shore topography, water depth, direction, and sediment movement, type of canals, usage (refuge, military, commercial), bridge dimensions, and bridge crossing specifications. Base map datasets attributes include boundaries, land use, demographics and businesses, environment, weather conditions, utility locations, public buildings and facilities.

Land use, demographic and business data are the basis for demand forecasting analyses that help planners assess the need for transportation facilities. Urban planning is interconnected with transportation planning and datasets such as zoning, property value, property vacancy, population, and travel statistics help produce current and projected population estimates for short and long-term transportation planning. Business data provide trucking and railroad companies with freight demands and allows them to offer services that cater to the business specific needs. Environmental data, such as the location of sensitive or hazardous areas,

contribute significantly to the decisions that are made about the location and the mode of transportation. 


\subsection{Benefits of Using GIS to Perform EIA}

GIS is a very powerful and useful tool and can be very efficient and effective for EIA (Colorado Department of Transportation, 2004). The following is a partial list of appropriate uses:

- Assessing physical/biological/human impacts.

- Using a wide variety of remote sensing data.

- Performing analyses at a variety of map scales.

- Developing standard rating systems for comparing disparate layers.

- Calculating additive effects.

- Measuring change over time (past, present, future, or other time intervals).

- Identifying locations where impacts are greatest or least.

- Identifying locations that are impacted from multiple actions or projects.

- Viewing non-physical features (e.g., political, zoning, or habitat boundaries).

\subsection{Constraints of Using GIS}

There are some intricate problems in implementation of GIS in environmental studies. Many of these are common to most applications and three categories can be distinguished according to Van (1992). The problems are:

- Non availability of proper spatial data.

- Lack of proper infrastructure within the government bodies.

- Shortage of skilled manpower in the government planning and development departments.

- GIS software is being more costly. 


\section{STUDY CASE: MID-PENINSULA TRANSPORTATION CORRIDOR}

\subsection{Study Area}

In this project the Mid-Peninsula Transportation Corridor case, which will be constructed at Niagara, Hamilton and Halton areas, was used. The Ministry of Transportation (MTO) has undertaken a significant amount of technical, forecasting and strategic planning work in the Niagara, Hamilton and Halton areas. This planning work has indicated that the existing transportation system does not have the capacity to support the planned population and economic growth of the area from the Niagara Peninsula to the Greater Toronto Area. The transportation analysis for the Niagara Peninsula Transportation Needs Assessment Study focused on the geographical area associated with the Regional Municipality of Niagara, the New City of Hamilton (formerly Regional Municipality of Hamilton-Wentworth) and the Region of Halton, including the City of Burlington (see Figure 6 for the study area map).

As the above municipalities are part of the broader Golden Horseshoe Area, the transportation linkages with the Greater Toronto Area (GTA), Haldimand County, and the KitchenerWaterloo-Guelph area, was considered as part of the study. In addition, given the proximity to the United States and the strategic role of the Niagara Peninsula as a major international gateway and economic corridor, the bridge crossings into New York State were examined in the context of projecting traffic growth on the transportation network (MPTC, 2005). 


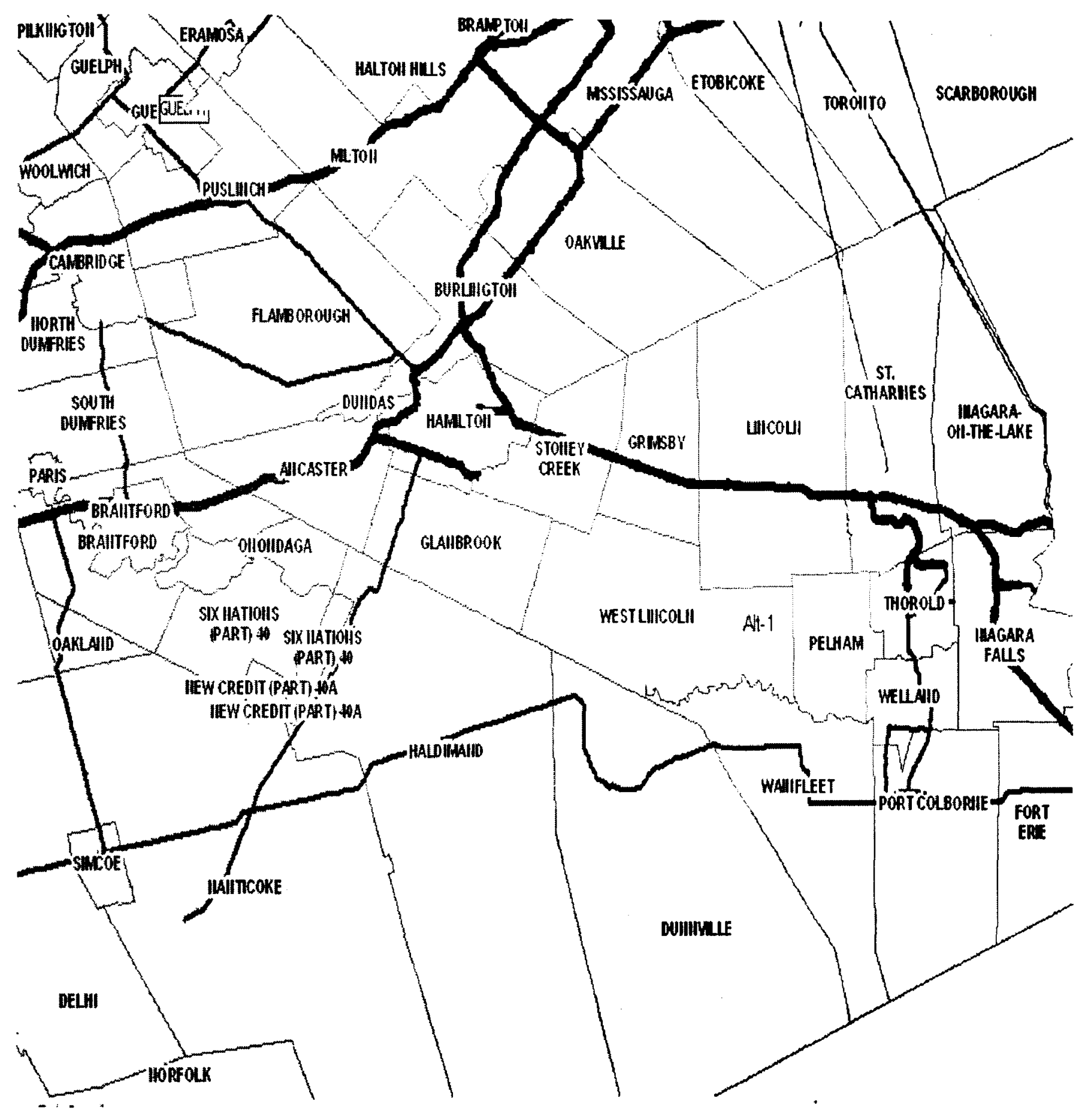

Figure 6 Study area 


\subsection{Study Objective}

The objective was to demonstrate the potential of GIS application for improving environmental impact assessment in the corridor planning. For this purpose a number of analyses were performed. All analyses are designed in such a way that they cover the most actual aspects of road management planning. The analyses simulate scenarios similar to those, usually investigated in the feasibility study and are made up as a comparative assessment of four alternatives.

\subsection{Present Situation}

The Ministry of Transportation (MTO) prepared a draft Niagara Peninsula Transportation Needs Assessment Study (June 2001) examining long-term transportation needs and options in the Niagara/Hamilton/Halton area within a 30-year planning horizon and found that additional transportation capacity was needed through the Niagara Peninsula into the Greater Toronto Area to accommodate future growth in the movement of people and goods. The corridor will increase road capacity in the peninsula, divert traffic and development away from the tender fruit farming areas below the escarpment, and promote development above the escarpment.

On the basis of the technical recommendations from the Needs Assessment, the Ministry of Transportation commenced the formal EA process, starting with an EA Terms of References (ToR), for the development of a new transportation corridor in the Niagara, Hamilton and Halton area (referred to as the Mid-Peninsula Transportation Corridor). In support of the EA ToR process, MTO completed extensive municipal, agency, stakeholder and public consultation between March 2002 and May 2003 and has submitted environmental assessment terms of reference for its proposal to develop a new transportation corridor, comprising a highway and potential future transitway, extending from the Niagara Falls/Fort Erie area through the Niagara Peninsula to the Hamilton/Halton area. The terms of reference were submitted under section 6(2) (c) of the Environmental Assessment Act and set out how the MTO plans to prepare the environmental assessment for the proposed highway/transitway.

This project has received the support of municipalities such as Niagara Region and Hamilton because they understand the importance of planning for the future and promoting economic growth away from features like the tender fruit lands. However, Burlington and Halton are not 
prepared to allow the environmental process to follow its normal course. Instead, they have chosen to appeal to the courts.

Over the short term (immediate to 2005), MTO will consult with the community on the needs assessment study findings and complete an environmental assessment (federal and provincial) to determine the preferred route location for the mid peninsula roadway. Once approved, MTO, with private sector assistance, is expected to proceed with the staged implementation of the project with tentative completion by 2011 .

Several approvals may be required for this project. The MTO will consult with approval agencies while preparing the EA to coordinate timing of approvals, approval requirements and to ensure that approvals are ultimately obtainable. Potential permits/approvals/authorizations required include, but are not limited to, the following:

- Navigable Waters Protection Act Approval (Federal Government)

- Fisheries Act Approval (Federal Government)

- Canadian Environmental Assessment Act Approval (Federal Government)

- Agreements from local utilities

- Railway Crossing Agreement

- Hydro Construction Agreements (Hydro One Networks)

- Tran Canada Pipeline Crossing Permit

- Inter-Provincial Pipeline Crossing Permit 


\subsection{Data}

In order to perform the analyses using GIS method many types of data are needed. GIS database consists of both spatial and non-spatial data. Data shown in Table 2 are obtained from CanMap Route Logistic 7.2 (Ontario) through Ryerson University Library. The spatial database included the following data:

Table 2 Proposed route generation data

\begin{tabular}{|c|c|c|}
\hline Subject & Format & Description \\
\hline Education & Shapefile & Schools \\
\hline Highways & Shapefile & $\begin{array}{l}\text { Expressway } \\
\text { Encasements }\end{array}$ \\
\hline Hydrogeography & Shapefile & $\begin{array}{l}\text { Hydrogeographic } \\
\text { Structure Lines }\end{array}$ \\
\hline Highways & Shapefile & Main Highways \\
\hline Hyrdrogeography & Shapefile & Lines \\
\hline Land Use & Shapefile & $\begin{array}{c}\text { Mostly in Urban } \\
\text { Areas }\end{array}$ \\
\hline $\begin{array}{l}\text { Municipal } \\
\text { Boundaries }\end{array}$ & Shapefile & Polygons \\
\hline Municipalities & Shapefile & Boundaries \\
\hline Parks & Shapefile & $\begin{array}{l}\text { Provincial Parks } \\
\text { (Points) }\end{array}$ \\
\hline Vegetation & Shapefile & $\begin{array}{c}\text { Wooded Areas, } \\
\text { Orchards }\end{array}$ \\
\hline Wetlands & Shapefile & Wetlands \\
\hline Hydrography & Shapefile & Rivers, Creeks, Lakes \\
\hline
\end{tabular}


The analysis was performed using the program ArcGIS. Add all layers in the ArcMap as illustrated in Figure 7.

Existing Vegetation area of study site:

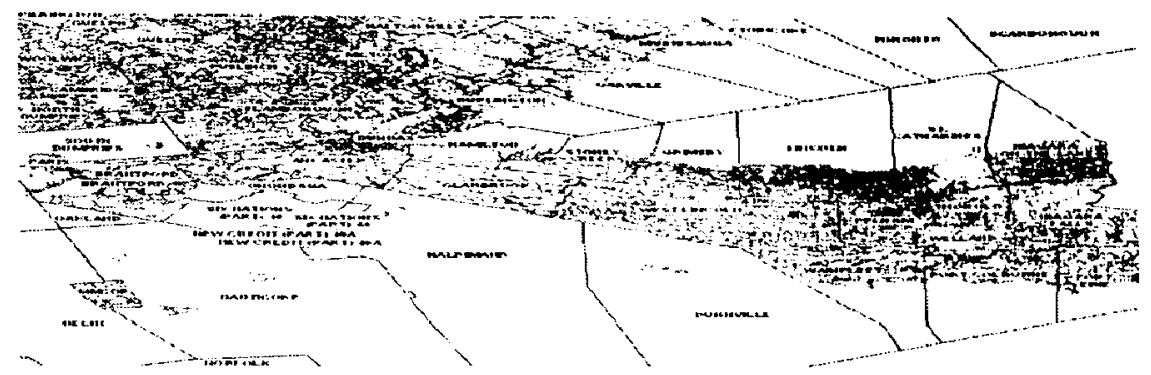

Existing Landuse area of study site:

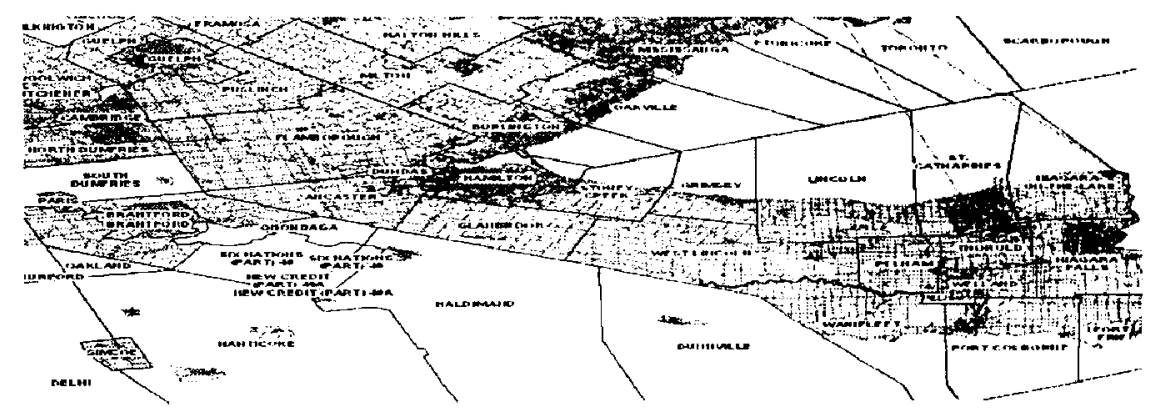

Existing Hydrography(River, creeks, lakes) of study site:

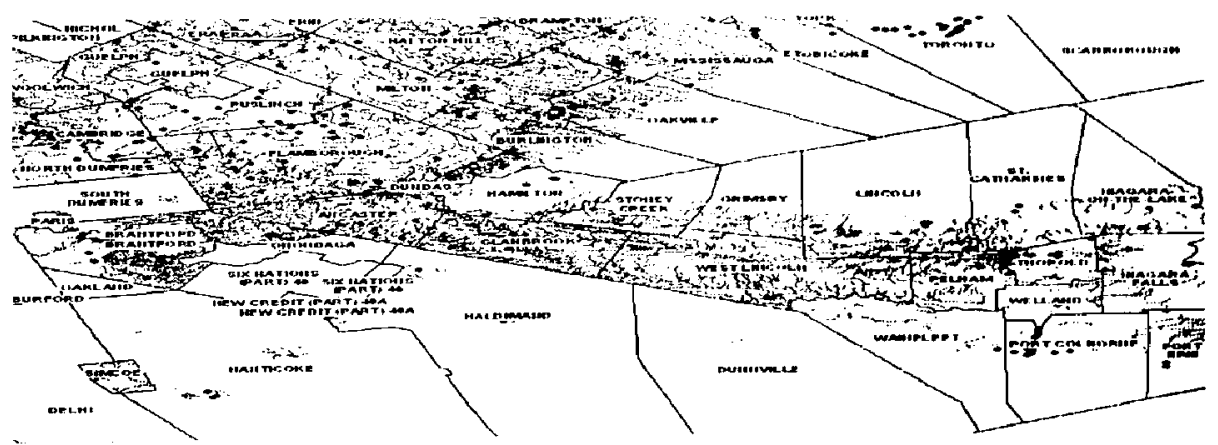

Existing Wetland of study site:

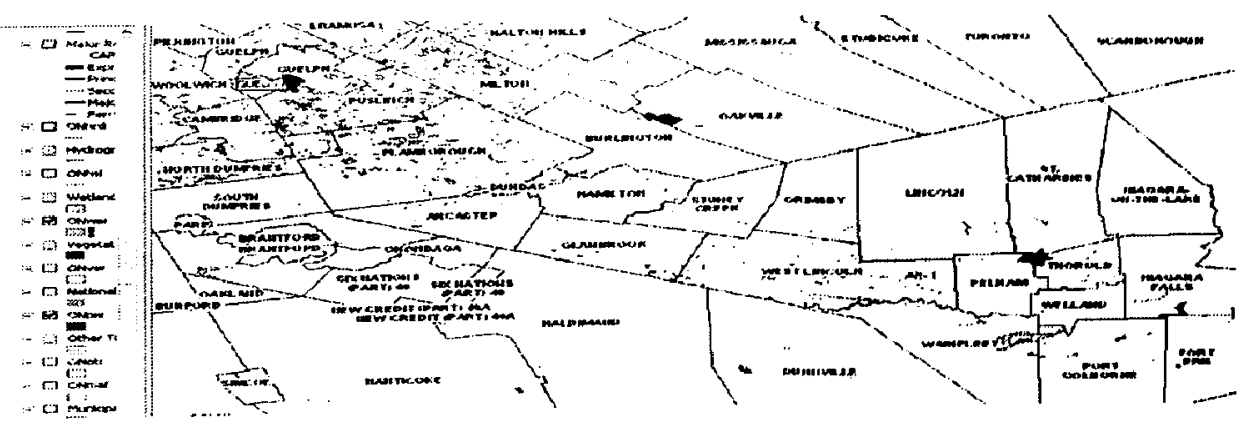

Figure 7 Existing natural and landuse layer of study area. 


\subsection{Criteria}

The overall assessment includes technical and economic prerequisites for different solutions and environmental impact assessment of the alternative corridors. The environmental assessment considers alternative routes for the proposed highway/transitway within the defined study area to determine a preferred route. Alternative routes will be generated and evaluated which connect to the QEW to the north and south of the City of Welland, and which connect to Highway 401 (east of Highway 6), Highway 407, Highway 6 and Highway 403 (in Hamilton).

Route features are created on Ontario highway layer as per above considered alternatives of the study area. The average right of way of the proposed MPTC is 60 meters wide to allow for future expansion to four lanes. So buffers of $60 \mathrm{~m}$ are created for all alternatives which are being considered and rename of these three alternatives are Alt-1, Alt-2, Alt-3 and Alt-4 respectively. As indicated on the map (see Figure 8), the solid line describes the all alternatives location of the mid peninsula roadway corridor. The final location of this corridor (and possible alternatives) is currently under review as part of the needs assessment study and environmental assessment Terms of Reference.

By comparing consequences of different alternatives proposed in the initial study, including zero-alternative, a final road corridor is suggested. At the same time the first decision on the road technical standards is being taken, for example, for which speed category the road should be designed and which level of priority it will get (national, regional, etc.) All national, environmental and public interests that can be affected by the construction of the road should be revealed and clearly stated at this stage. Public opinions are also taken into consideration. When the choice of the road corridor is finally approved the planning process goes further to the stage of road design. 


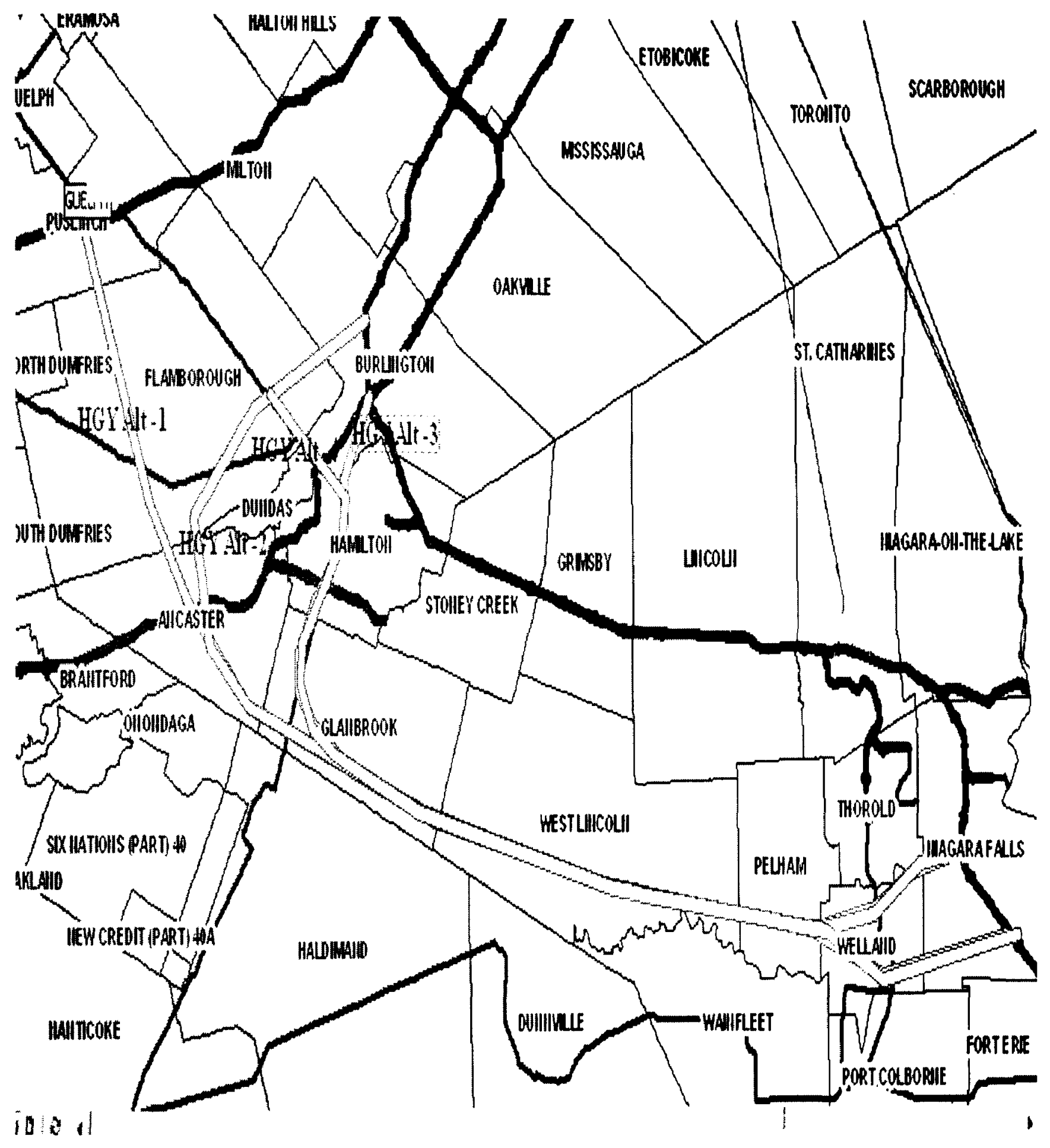

Figure 8 Proposed four alternatives 


\subsection{Assessment of Alternatives}

The evaluation of the natural environment considers the comparative impacts of each alternative on the following criteria.

- The degree to which the proposed transportation system modification minimizes resource consumption (e.g., mineral, aggregate, and agricultural land).

- The degree to which the proposed transportation system modification minimizes vegetation areas, wetlands, and habitat.

- The degree to which the proposed transportation system modification supports federal, provincial and municipal environmental protection policies.

\subsection{Analysis}

For Niagara Peninsula corridor to be able to choose the best alternative a detailed EIA will be needed. Several road corridors were proposed as an improvement measure during the planning stage. In order to study the potential alternative for improving the planning process at the Niagara Peninsula corridor, several problems simulating real situations were solved by overlay operation and were performed using the program ArcGIS. The problems are presented in the form of six analyses on the basis of limited environmental data.

\subsubsection{Analysis 1-Municipality Areas Conflict}

Among the major tasks of EIA during the feasibility study is to define and describe the areas of conflicts, i.e., areas where the corridor will cross natural, residential, or cultural environments and places that are classified as national or public interests. In order to be able to analyse the consequences of the road construction it is necessary to know how the landscape and people will be affected. Claiming of land may result in removal of houses, buildings, ancient remains, etc. To be able to assess the caused damage, and, thus, the compensation that all affected people have a right for, it is important to know which estates will be intersected with the road, how many people will be affected in each municipality area and what value the estates have. Figure 9 shows the number of municipality and population that will be affected due to the construction of the MPTC. 


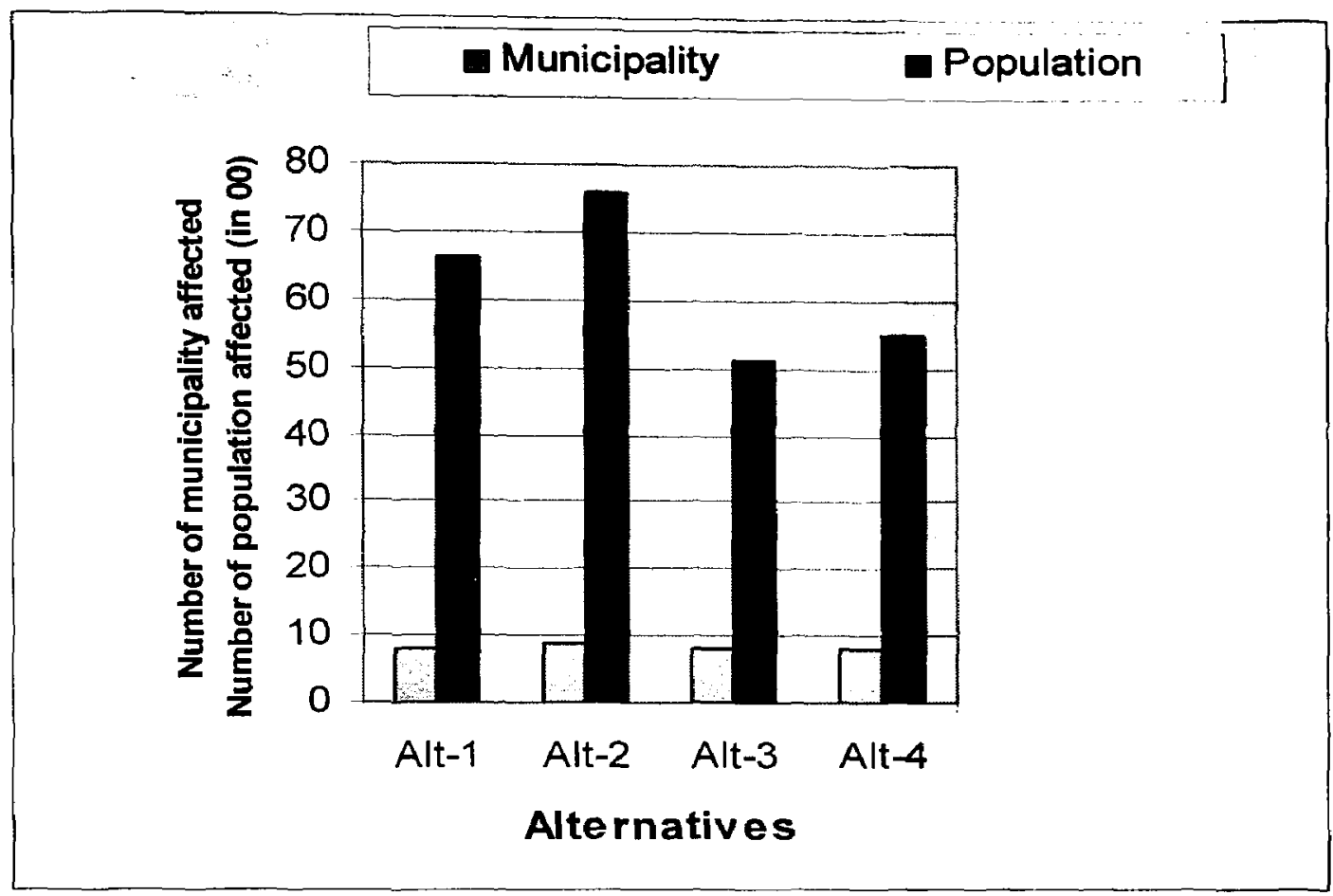

Figure 9 Graphical representations of affected municipality and population

\subsubsection{Analysis 2 - Transportation of Dangerous Goods}

Transportation of dangerous goods has increased tremendously during the last years and is expected to grow in the nearest future. In order to make the transportation of dangerous goods as safe as possible, risk analyses should be performed during planning and location of new roads. Risk analyses imply "what if" scenarios where the potential risk of possible accidents is studied. The task of this analysis is to demonstrate the application of the GIS-method in risk analysis, where it is needed to find out what is lying in the zone of risk. During the transportation of dangerous goods accident may occur at any point of proposed corridor and the risk area around the point of accident is considered 500 meters, so a buffer of $500 \mathrm{~m}$ is chosen as risk zone for all alternatives (see Figure 10). The number of municipality and people those were affected can be found or how much land or streamlines may be polluted can be calculated (see Figure 11). 


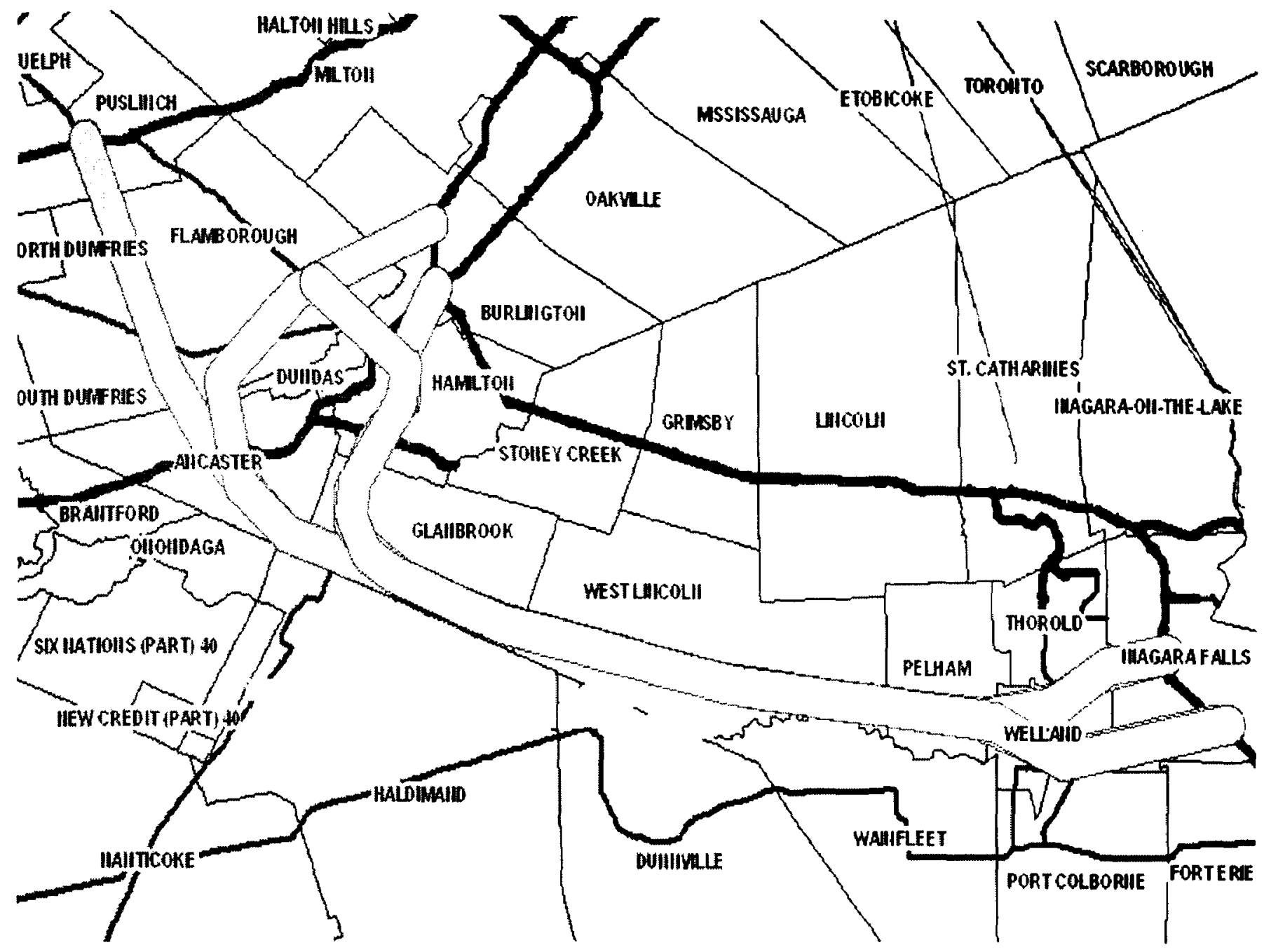

Figure 10 The zone of risk due to accident has a buffer of 500 meters. 


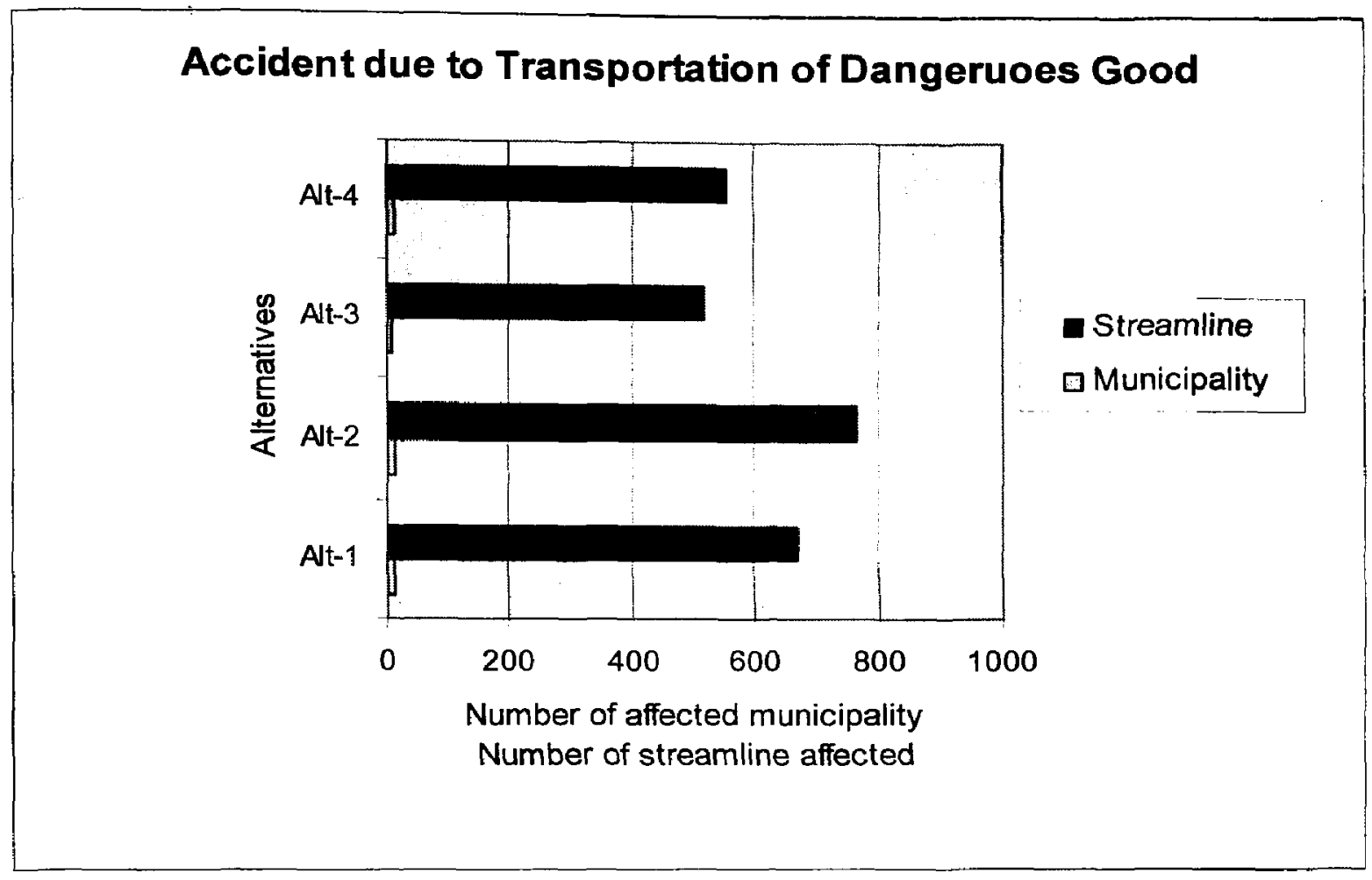

Figure 11 Graph showing the number of affected municipality and streamline.

\subsubsection{Analysis 3 - Landuse Conflicts}

It is necessary to make an overall but comprehensive assessment of how the different types of land use, for example residential, industrial or agricultural area, will be affected and to know how much of land or water areas will be claimed and how the landscape and people will be affected for the construction of the road. This analysis is going to show how the GIS-method can be used to produce the data on land use distribution inside the road corridor (see Figure 12) and to demonstrate, as an example, which of road corridors has less impact on valuable agricultural land. And the results of different alternative corridors are presented in graphical form (Figure13). 


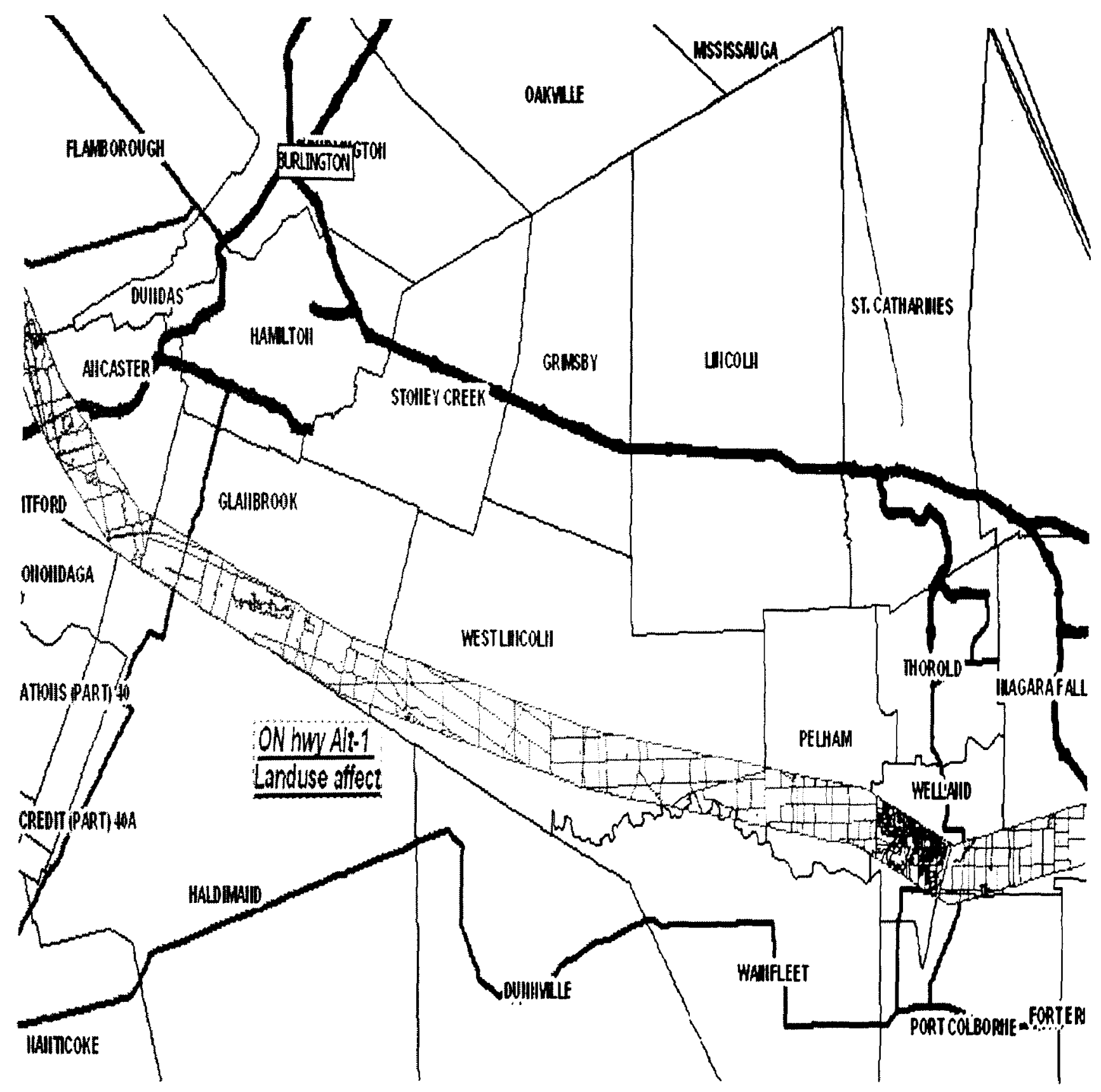

Figure 12 Distribution of different land use classes within the corridor Alt-1. 


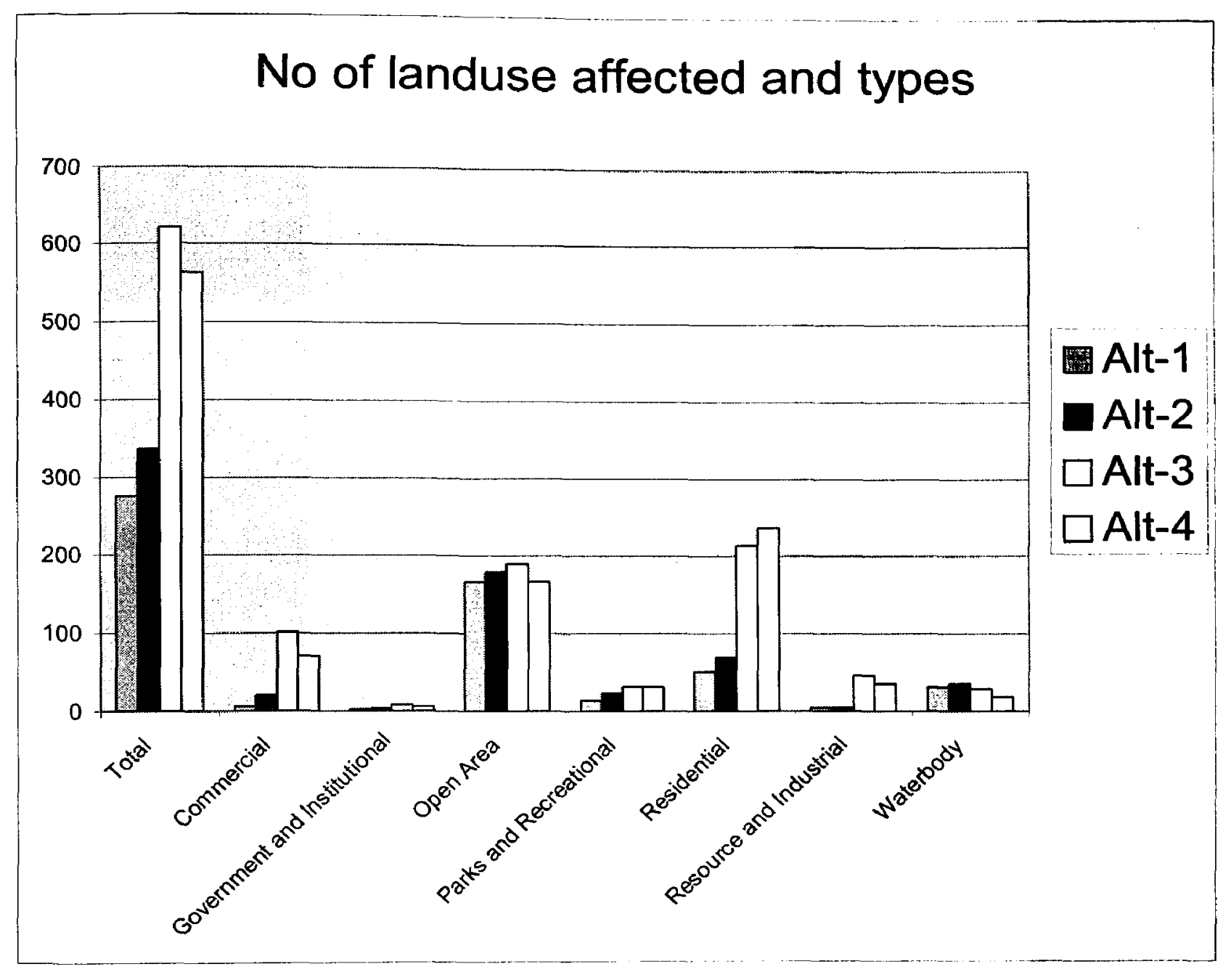

Figure 13 Land use classes shown in graph for different alternatives.

\subsubsection{Analysis 4-Hydrography}

Roads function as barriers for water streams and can have negative effects on surface and ground water movement. Moreover, roads can have an impact on water streams and rivers in the form of pollution from cars petroleum products and from transportation of polluting goods. To find out how many rivers/creeks or streams are intersected due to construction of corridor and how much area inside the zone of risk is agricultural land, perform the same analysis for the whole study area, assuming that each point can be a potential center of accident. The results of different alternative corridors are presented in graphical form in Figure 14. 


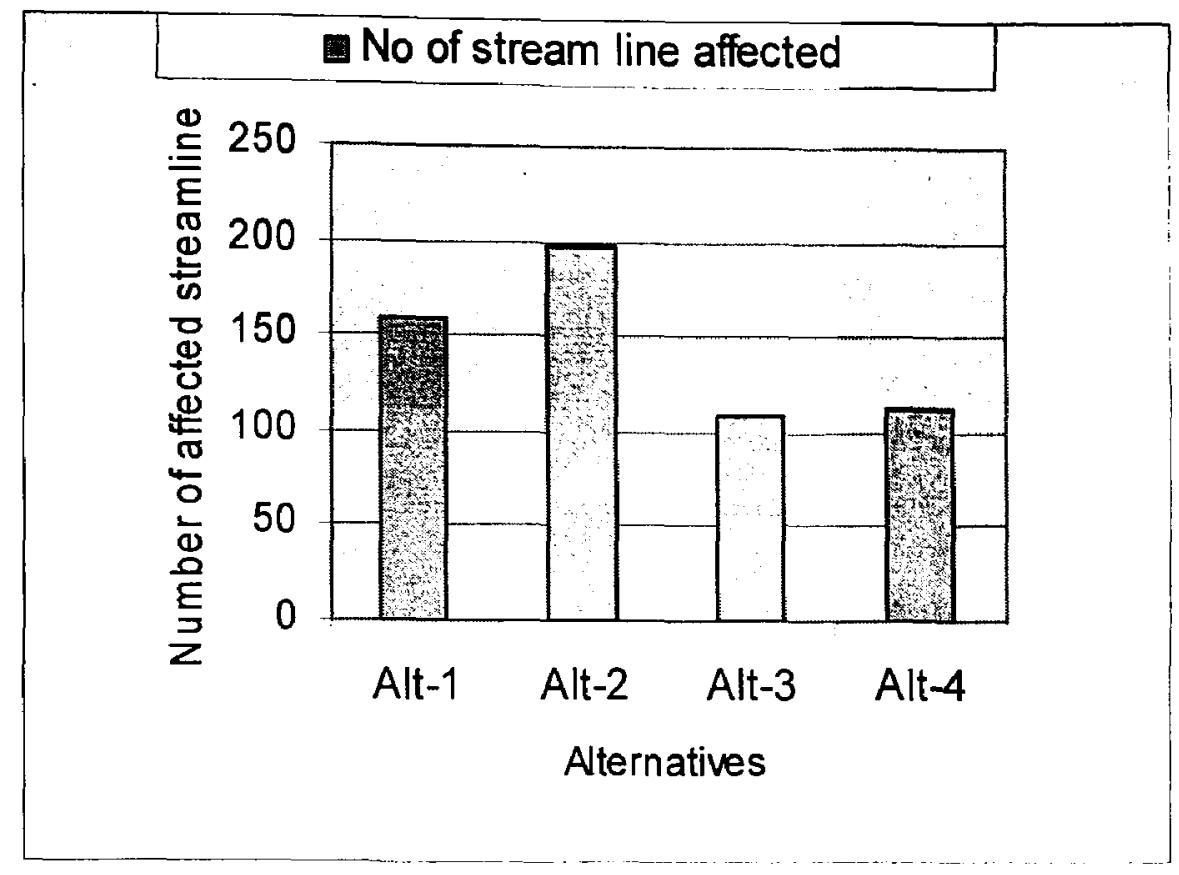

Figure 14 Numbers of affected stream lines are shown in graphs for different alternatives.

\subsubsection{Analysis 5-Vegetation Conflicts}

Another important matter that is studied during EIA is the content of the transportation corridor or road zone. In order to evaluate the impact of different alternatives, the decisionmaker needs to know the type and value of the environment inside the corridor or road zone that will disappear during the construction. In case the road is crossing the natural environment, it is necessary to make an overall but comprehensive assessment of how the different type's vegetation or forest area will be changed. Figure 15 shows the vegetation layer that was lying inside the road corridor for Alt-1 and Figure 16 is the graphical representation of affected vegetation area for all alternatives. 


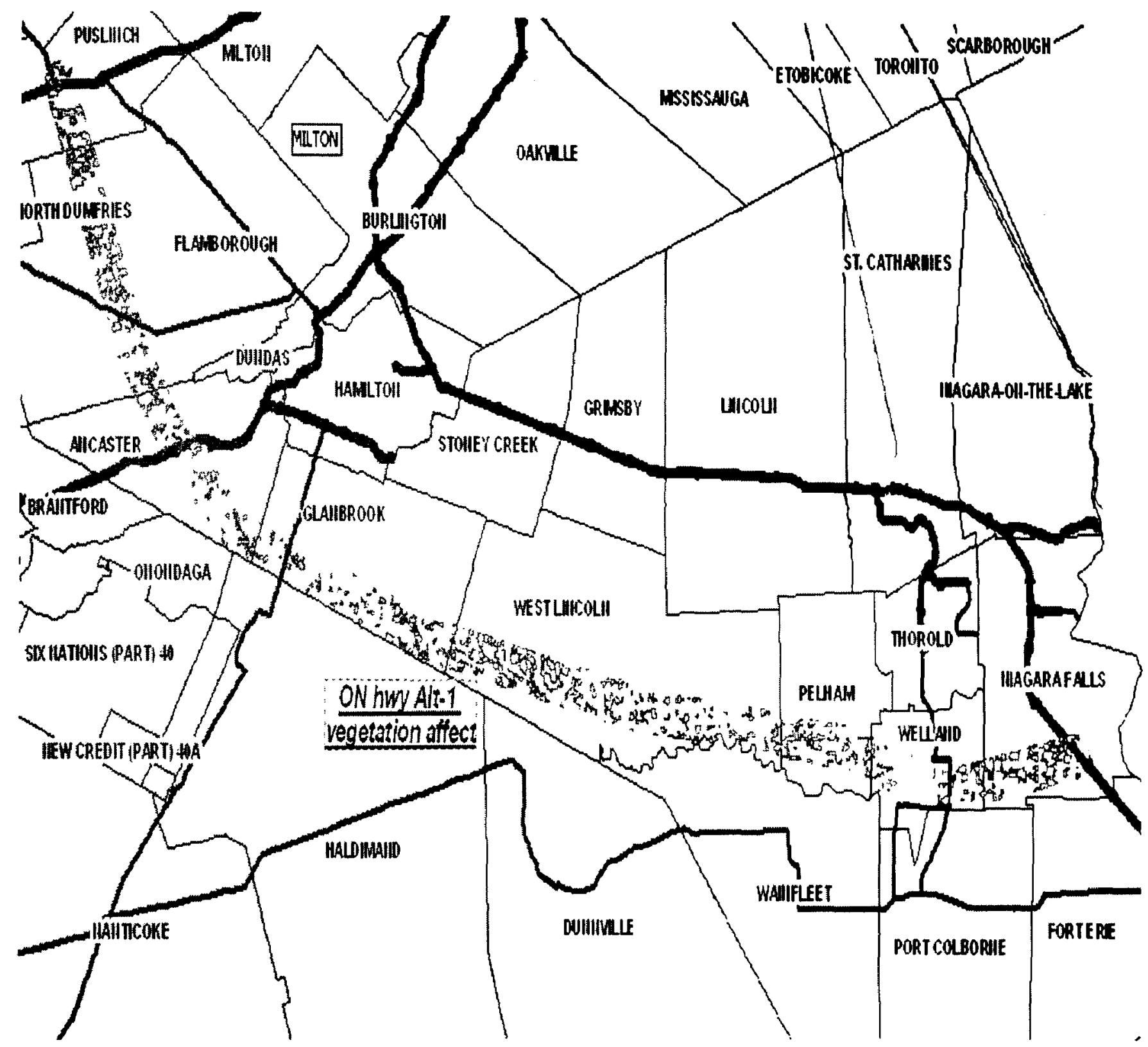

Figure 15 Affected vegetation area due to construction of new corridor. 


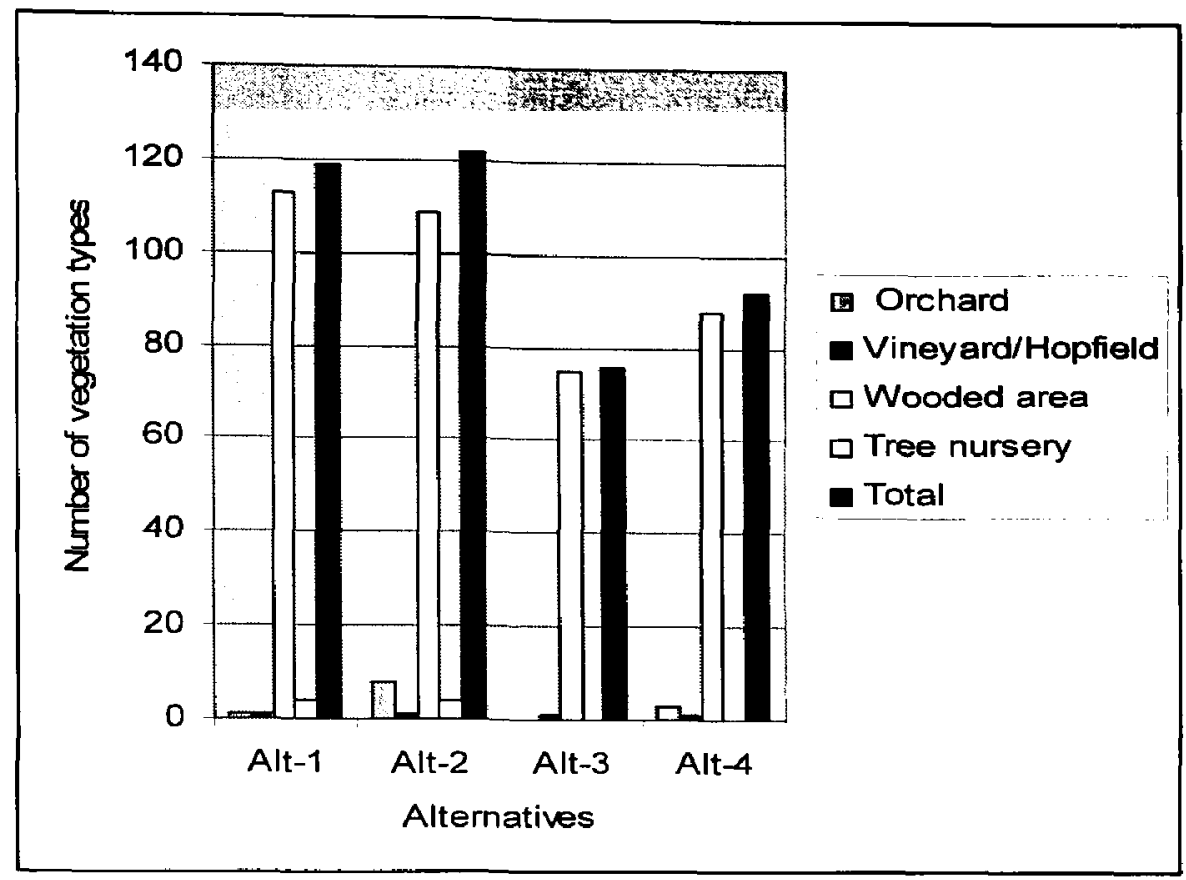

Figure 16 Graphical representation of affected vegetation.

\section{Wetland}

The affected wetlands and types can be seen in the attribute table. Figure 17 presented the results of different alternative corridors in graphical form.

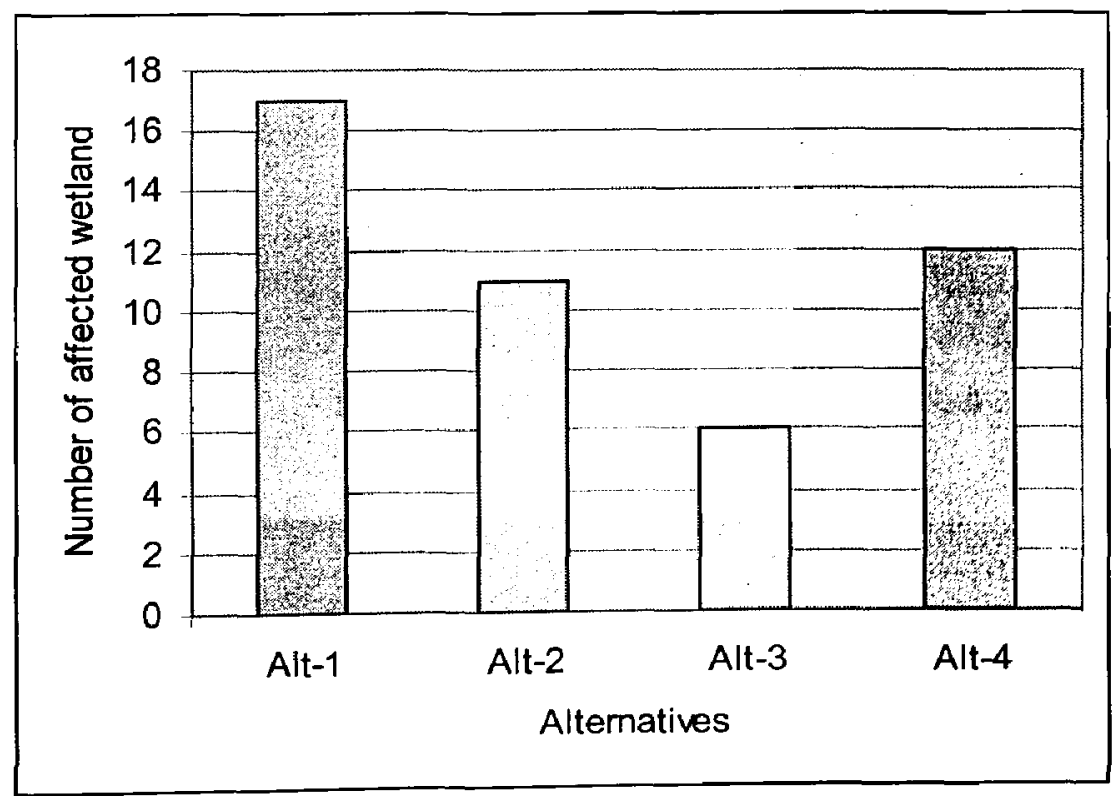

Figure 17 Number of affected wetland is shown in graphs. 


\subsubsection{Analysis 6-Educational Institute}

To analyze the consequences of the road construction it is necessary to know how many educational institutes will be fall within the proposed corridor and that's why how many students will be affected. Figure 18 shows the attribute table where name and number of affected school(s) can be found.

\begin{tabular}{|c|c|c|c|c|c|c|}
\hline & FID & Shape' & IIAME & PREC_CODE & ATTRIBCODE & POI_ID \\
\hline \multirow[t]{2}{*}{1} & 0 & Point & ECOLE SECONDAIRE CATHOLIQUE JEAN-VANUER & 1 & 1 & POl2154658 \\
\hline & & Point & ST MARY SCHOOL & 1 & 1 & POl2157606 \\
\hline
\end{tabular}

Figure 18 Attribute tables of affected institutions for Alt-1.

And the results (number of affected institutes) of different alternative corridors are presented in graphical form (see Figure 19).

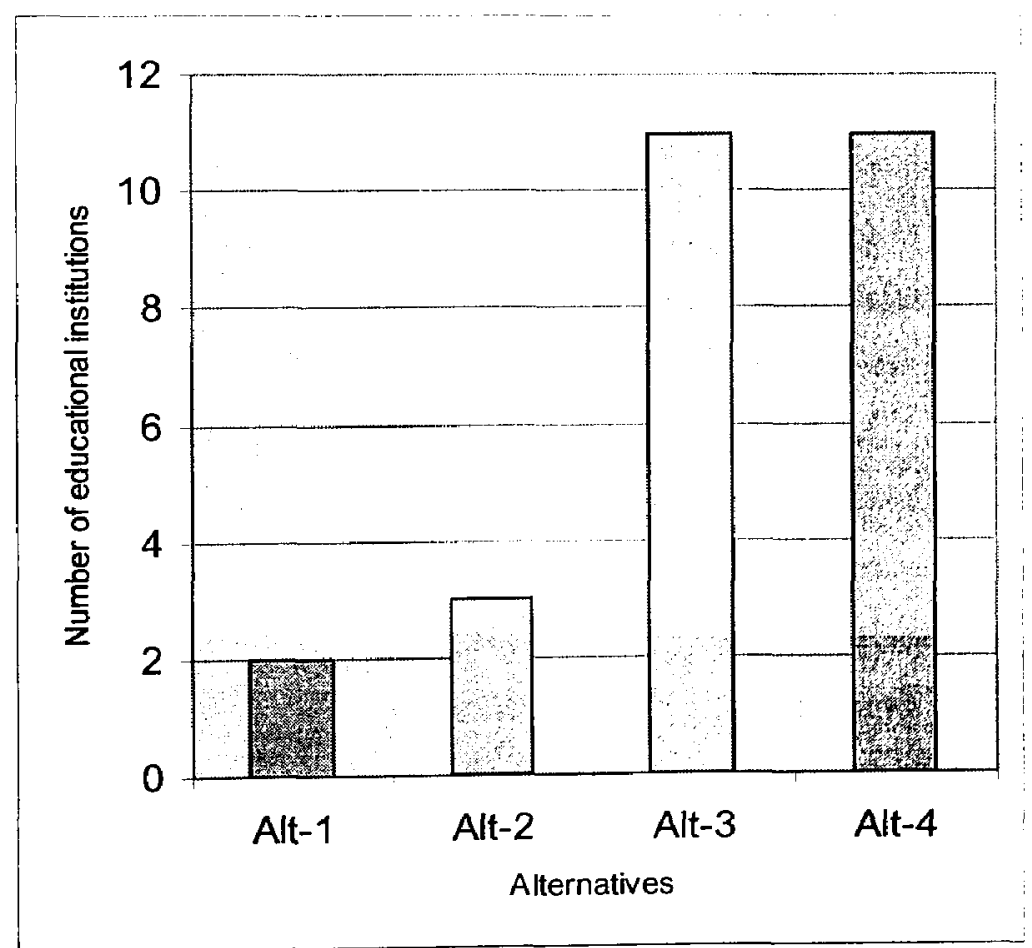

Figure 19 Number of affected institutions is shown in graphs. 


\subsection{Comparison Table}

The study solved all the tasks by overlay techniques to assessments of environmental impact. Table 3 below listed the various environmental impacts associated with alternatives.

Table 3 Impacts associated with alternatives.

\begin{tabular}{|c|c|c|c|c|}
\hline Alternatives & Alt-1 & Alt-2 & Alt-3 & Alt-4 \\
\hline $\begin{array}{l}\text { Analysis-1 } \\
\text { No of municipal } \\
\text { affected }\end{array}$ & 08 & 09 & 08 & 08 \\
\hline $\begin{array}{l}\text { Analysis-2 } \\
\text { Accident due to } \\
\text { transportation of } \\
\text { dangeruoes good }\end{array}$ & $\begin{array}{l}\text { Within } 1000 \mathrm{~m} \\
\text { buffer risk zone } \\
\text { Municipality=12 } \\
\text { Streamline }=668\end{array}$ & $\begin{array}{l}\text { Within } 1000 \mathrm{~m} \\
\text { buffer risk zone } \\
\text { Municipality=13 } \\
\text { Streamline }=764\end{array}$ & $\begin{array}{l}\text { Within } 1000 \mathrm{~m} \\
\text { buffer risk zone } \\
\text { Municipality }=9 \\
\text { Streamline }=516\end{array}$ & $\begin{array}{l}\text { Within } 1000 \mathrm{~m} \\
\text { buffer risk zone } \\
\text { Municipality }=11 \\
\text { Streamline }=554\end{array}$ \\
\hline $\begin{array}{l}\text { Analysis-3 } \\
\text { No of landuse } \\
\text { affected and types }\end{array}$ & $\begin{array}{l}\text { Total-276 } \\
\text { Commercial-6 } \\
\text { Government and } \\
\text { Institutional=2 } \\
\text { Open Area=167 } \\
\text { Parks and } \\
\text { Recreational=14 } \\
\text { Residential=51 } \\
\text { Resource and } \\
\text { Industrial=5 } \\
\text { Waterbody=31 }\end{array}$ & $\begin{array}{l}\text { Total-621 } \\
\text { Commercial=101 } \\
\text { Government and } \\
\text { Institutional=9 } \\
\text { Open Area=190 } \\
\text { Parks and } \\
\text { Recreational=32 } \\
\text { Residential=214 } \\
\text { Resource and } \\
\text { Industrial=46 } \\
\text { Waterbody=29 }\end{array}$ & $\begin{array}{l}\text { Total-337 } \\
\text { Commercial=21 } \\
\text { Government and } \\
\text { Institutional=4 } \\
\text { Open Area=180 } \\
\text { Parks and } \\
\text { Recreational=23 } \\
\text { Residential=69 } \\
\text { Resource and } \\
\text { Industrial=5 } \\
\text { Waterbody=35 }\end{array}$ & $\begin{array}{l}\text { Total-563 } \\
\text { Commercial=70 } \\
\text { Government and } \\
\text { Institutional=6 } \\
\text { Open Area=166 } \\
\text { Parks and } \\
\text { Recreational=31 } \\
\text { Residential=237 } \\
\text { Resource and } \\
\text { Industrial=35 } \\
\text { Waterbody=18 }\end{array}$ \\
\hline
\end{tabular}




\begin{tabular}{|c|c|c|c|c|}
\hline Alternatives & Alt-1 & Alt-2 & Alt-3 & Alt-4 \\
\hline $\begin{array}{l}\text { Analysis-4 } \\
\text { No of stream } \\
\text { line affected }\end{array}$ & 160 & 197 & 108 & 112 \\
\hline $\begin{array}{l}\text { Analysis-5 } \\
\text { No of vegetation } \\
\text { affected }\end{array}$ & $\begin{array}{l}\text { Vegetation total: } \\
119 \\
\text { Orchard=1 } \\
\text { Vineyard/ } \\
\text { Hopfield=1 } \\
\text { Wooded area }=113 \\
\text { Tree nursery }=4\end{array}$ & $\begin{array}{l}\text { Vegetation total: } \\
122 \\
\text { Orchard=8 } \\
\text { Vineyard/ } \\
\text { Hopfield=1 } \\
\text { Wooded } \\
\text { area }=109 \\
\text { Tree nursery=4 }\end{array}$ & $\begin{array}{l}\text { Vegetation total: } \\
76 \\
\text { Orchard }=0 \\
\text { Vineyard/ } \\
\text { Hopfield }=1 \\
\text { Wooded area }=75 \\
\text { Tree nursery }=0\end{array}$ & $\begin{array}{l}\text { Vegetation total: } \\
92 \\
\text { Orchard }=3 \\
\text { Vineyard/ } \\
\text { Hopfield }=1 \\
\text { Wooded area }=88 \\
\text { Tree nursery }=0\end{array}$ \\
\hline Wetland & 17 & 11 & 6 & 12 \\
\hline $\begin{array}{l}\text { Analysis-6 } \\
\text { No of } \\
\text { educational } \\
\text { Institute affected }\end{array}$ & 2 & 3 & 11 & 11 \\
\hline
\end{tabular}




\subsection{Solving by Spatial Modeling}

Spatial modeling is also used to visualize and analyze the anticipated effects of a proposed corridor on the environment. Spatial analysis is a process of modeling, examining, and interpreting model results useful for evaluating suitability and capability, for estimating and predicting, and for interpreting and understanding. In GIS, there are four traditional types of spatial analysis: spatial overlay and contiguity analysis, surface analysis, linear analysis, and raster analysis. It includes such GIS functions as topological overlay, buffer generation, and spatial or network modeling.

In reality significant environmental constraints cannot be avoided for any corridor alternative but environmental impacts can be minimized. So, first find out the locations where all the environmental impacts are avoided and than take decision which alternative is lying most closely. Following environmental constraints are considered for best location.

The list of constraints for best location:

- It must be within the municipality of Niagara Falls, Welland, Pelham, West Lincoln, Glanbrook, Ancaster, Flamborough, Puslinch, Thorold and Burlington.

- It cannot be within $100 \mathrm{~m}$ wetland.

- It cannot be within $500 \mathrm{~m}$ park area.

- It cannot be located where the land cover contains vegetation.

- It cannot be within $100 \mathrm{~m}$ of stream line.

- It cannot be within $100 \mathrm{~m}$ of hydrography structure.

- It cannot be within $500 \mathrm{~m}$ of educational Institution.

Depending upon the above constraints the systematic process of site selection is as shown in Figure 20. All works were performed using the program ArcGIS and suitable location map is shown in Figure 21. 


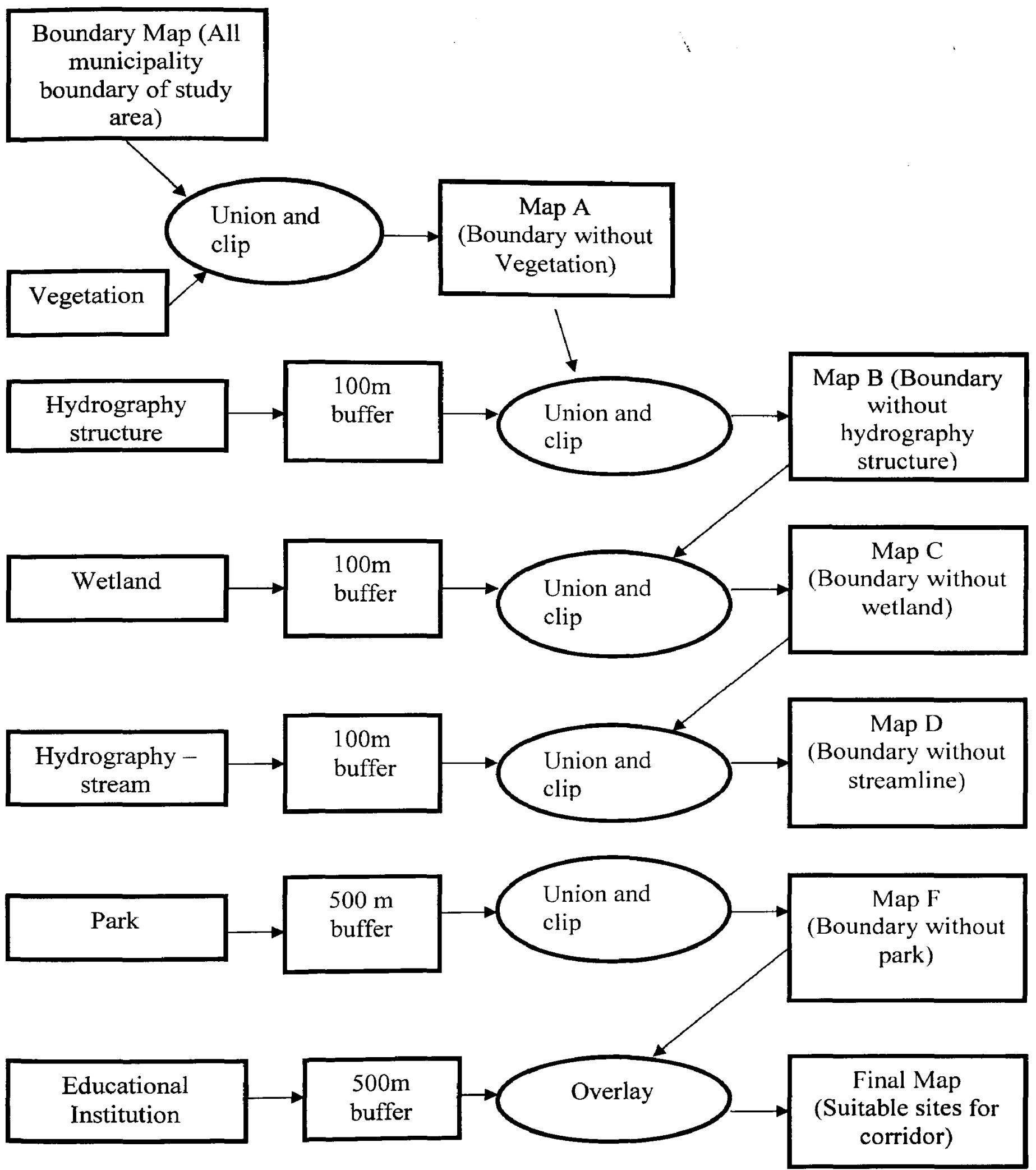

Figure 20 Corridor site selection process. 


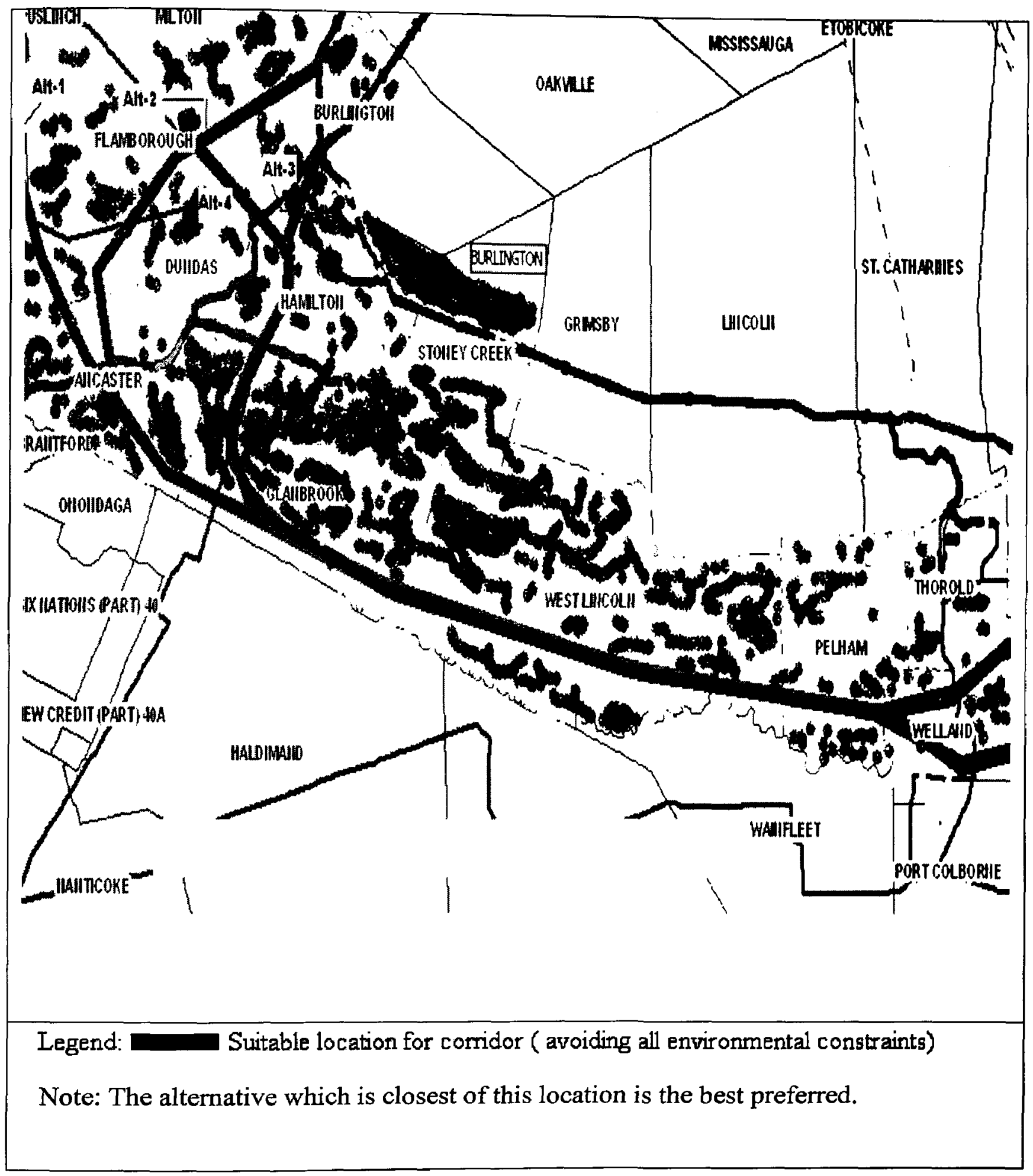

Figure 21 Suitable location for corridor. 


\section{CONCLUDING REMARKS}

MTO is undertaking the planning and Environmental Assessment (EA) process to determine a preferred route for the proposed Mid-Peninsula Transportation Corridor. The work plans outline objectives for generating routes to minimize adverse environmental impacts, and describe how the impacts are associated with route. Route selection process is based on a combination of engineering, traffic and economic, as well as environmental factors. The consideration of alternative route or corridor alignments is the most effective way to select a preferred location in which a transportation scheme can avoid significant environmental effects.

This report discussed how and when EIA it needed for highway projects and what is the process for which the EIA has to be done and how GIS can serve as an important tool for environmental scoping. It didnot address the issues related to the policy level. EIA should get proper attention in the process of decision-making. This can be reached by improving the quality of information that forms the basis for decision-making; in other words, the basis for decision-making should be more comprehensive. Thus, the aim of EIA is to contribute to the decision-making and provide decision-makers with knowledge about the conceivable effects from the project or any other activity on the environment, people's health and natural resources. The development of Environmental Impact Assessment (EIA) tools and methodologies is critical to ensuring that all potentially adverse impacts are identified and assessed, and are given consideration in the decision-making process.

The EIA study utilized a process that seeks to determine the environmental effects. The analyses of spatial data are an essential part of EIA. The study showed that GIS is applicable for managing and analyzing spatial data for EIA purposes. Overlay maps are easy to use and understand, and are popular in practice. It is a very important way of showing the spatial distribution of impacts. It also leads intrinsically to an impact decision. Therefore, this study has demonstrated overlay techniques to assess of environmental impacts. Spatial modeling is also used to visualize and analyze the anticipated effects of proposed corridor on the 
environment. GIS technology gives good outcomes when used to visualize information in forms of map.

It is difficult to comment on the specific environmental impacts associated with a MidPeninsula Transportation Corridor and recommend a preferred route location alternative. There is a high level of complexity into the preferred route-selection process. Throughout the study area, it is expected that during the generation and evaluation of alternatives, various routes would have common points where routes intersect. In such cases, further analysis would be taken to determine preferred routes for portions of the study area rather than comprehensively examining all combinations of routes for the entire corridor. Again one alternative may be better for an environmental constraint whereas other alternatives may be better for another one constraints.

Observations revealed Alt-1 is very poorly located compared to others alternatives regarding impacts on wetlands. Alt 1 crossed through previously undeveloped land which had plenty of wetlands, whereas Alt-3 is located in relatively urban areas with less wetland. With respect to landuse, Alt- 1 affected minimum agricultural land (open area), where Alt-2 scored high on land use change because it travels through a main residential area, which would require appropriation of much of that land. With respect to noise pollution, Alt-2 and Alt-4 are poorest because they crossed through a major residential area, whereas Alt-1 and Alt-3 are relatively better as they are further away from residential development. In the case of educational institutions Alt-1 and Alt-2 affected minimum numbers, whereas higher numbers of educational institutions are affected in Alt-3 and Alt-4. Alt-3 scored very low on stream crossings compared to other three alternatives. With respect to vegetation area Alt-3 is located in relatively suitable location affecting the minimum numbers of wooded area. However from the criteria and above discussion, this limited effort observed that Alt-3 would be preferred alternative with the least impacts, although it's impact is somewhat higher than others, but it was not by a large enough margin to be considered significant.

The terrestrial habitat, aquatic habitat, ecosystem integrity/connectivity, air quality, noise, archaeology, heritage and economic factors are not envisaged in this study. However, there is always an opportunity to improve the method or to use better input data, which will improve the result. By being aware of potential and problems of the technique it can be much easier to 
establish well functioning application of GIS. Overall the study presented the possibilities for improving EIA performance by using GIS. This decision-making process includes determining corridor alternatives, their evaluation and comparison, and choosing the best environmental option. Features of the environment that needs to be considered in this decision-making process can either be issues where the corridor potentially impacts the environment or issues where the environment potentially impacts on the corridor. These issues are identified for every project, mapped and assessed to determine the potential significance of their impact. To determine and compare corridor alternatives, the spatial location of these issues, their spatial relation to each other and the potential significance of their impact needs to be considered. Further environmental investigations, including secondary source reviews and field investigations will be required to generate route alternatives, assess the impacts of route alternatives and complete the evaluation that will lead to a preferred route. 


\section{REFERENCES}

Agrawal, M. and Dikshit, K., (2003), "Significance of Spatial Data and GIS for EIA of Highway Projects".

Alexander, S. and Waters, N., (2000), "The Effects of Highway Transportation Corridors on Wildlife- A Case Study of Banff National Park" Transportation Research, 8(1): 307-320.

Amar, H., (2002), "Environmental Considerations during Transportation Planning" Roger University of Central Florida.

Antunes, P. and Santos, R., (2001), "The Application of Geographical Information Systems to Determine Environmental Impact Significance" EIA review, 21(6): 511-535.

Arkansas Highway and Transportation Department (AHTD), USA

Batty, M., (1993), "The Geography of Cyberspace, Environment and Planning" Planning and Design, 20(6):615-616.

Brian, B. and Hong, L., (2004), "GIS-Based Cumulative Effects Assessment" Colorado Department of Transportation.

Brown, A. and Affum, J., (2002), "A GIS-Based Environmental Modelling System for Transportation Planners" Environment and Urban Systems, 26: 577-590.

Burrough, P., (1986), "Principles of Geographical Information Systems for Land Resources Assessment".

Camougis, G., (1981) "Environment Biology for Engineering, A Guide to Environmental Assessment".

Canter, L., (1996), “Environmental Impact Assessment”.

Clark, D., (1981), "The Aims and Objectives of Environmental Impact Assessment" NATO Advanced Study Institute on Environmental Impact Assessment.

Colorado Department of Transportation Development, (2001), GIS Section. 
Council on Environmental Quality, (1997), "Cumulative Effects Handbook".

Davis, B., (1996), “Geographic Information Systems: A Visual Approach”.

Department of Transport and the Regions, (1997), "Mitigation Measures in Environmental Statements".

Eedy, W., (1995), "The use of GIS in Environmental Assessment. International Association for Impact Assessment (IAIA)" 13(2):199-206.

El-Raey, M., (2003), "Environmental Impact Assessment of Projects" Work Shop at the Institute of Graduate Studies and Research, University of Alexandria, Egypt.

Erickson, A., (1994), “A Practical Guide to Environmental Impact Assessment".

Final Report of the Strategic Environmental Assessment, (1999), "Review of the Environmental Impact Study (EIS) of the Santa Cruz Transportation Corridor".

Ghaffar, K., (2001), "GIS to support EIA" International Institute of Aerospace Survey and Earth Science, Netherlands.

Gipps, P. and Barnett, G., (2001), "New Technologies for Transport Route Selection" Transportation Research, 9(2): 135-154.

Gramangis, E., (1981), "Methods of Environmental Impact Assessment".

Griffith, C., (1980), "Geographic Information Systems and Environmental Impact Assessment" Environmental Management, 4(1):21-25.

Gunasekera, R., (2004), "Use of GIS for Environmental Impact Assessment: an Interdisciplinary Approach” Interdisciplinary Science Reviews, 29(1), pp. 37-48(12).

Ministry of Transportation, (2004), "Highway 7 Kitchener to Guelph-Amendment to the Environmental Assessment Report".

Hossein, Y., (2004), "Application of GIS in the EIA".

Joao, E. and Fonseca, A., (1996), "The Role of GIS in Improving EA Effectiveness: Theory versus Practice", International Association for Impact Assessment, 14: 371-385. 
Joesf, L., (1994), "Rapid Urban Environment Assessment Lessons From the Cities in the Developing World" Urban Management Programme, World Bank.

Johnston, C., Bonde, N. and Niemi, G., (1988), "GIS for Cumulative Impact Assessment" Photogrammetric Engineering and Remote Sensing, 54(11): 1609-1615.

Keith, C., Bradley, P. and Micheal, P., (2002) "GIS and Environmental Modeling".

Klungboonkrong, P. and Taylor, M., (1999), “An Integrated Planning Tool for Evaluating Road Environmental Impacts", 14(5): 335-345.

Li, X., Wang, W. and Deng, X., 1999, "GIS Based Map Overlay Method for Comprehensive Assessment of Road Environmental Impact” Transportation Research, 4: 147-158.

Looijen, J., (2000), "EIA using GIS and MCE" ITC, Netherlands.

Malczewski, J., (1999), “GIS and Multicriteria Decision Analysis” New York.

Minnesota Department of Transportation, USA.

Morris, P. and Therivel, R., (1995), "Methods of Environmental Impact Assessment".

Munn, R., (1975), “Environmental Impact Assessment: Principles and Procedures" SCOPE report 5.

Muthusamy, N. and Ramalingam, M., (2003), “Environmental Impact Assessment for Urban Planning and Development using GIS" $290-299$.

Niagara to GTA Corridor, (2005), "Environmental Assessment Terms of Reference".

Niagara to GTA Corridor, (2003), "Need Assessment Terms of Reference".

Petch, J., (1993), "GIS and Decision Making".

Rebolj, D. and Sturm, P., (1999), "A GIS Based Component-Oriented Integrated System for Estimation, Visualization and Analysis of Road Traffic Air Pollution" Environmental Modelling and Software, 14(6): 531-539.

Rich, J. and Nielson, O., (2004), “Assessment of Traffic Noise Impacts. International Journal of Environmental Studies" 61(6): 16-29. 
Rodriguez, J. and Bachiller, A., (1995) "GIS and Methods of EIA" 320-324.

Sadek, S., Bedran, M. and Kaysi, I., (1999), "GIS Platform for Multicriteria Evaluation of Route Alignments" Journal of Transportation Engineering, 125(2): 144-151.

Sinha, S., (1998), “Environmental Impact Assessment: An Effective Management Tool”.

Smith, D., (1993), "Pygmalion: An Executable Electronic Blackboard”. 19-47.

Strömquist, L. and Larsson, R., (1994), "Project Design on Coastal Resource Mapping for Environmental Planning and Management" Institute of Earth Sciences, Uppsala University.

Vägverket (1995), "Environmental Impact Assessment for Roads" Sweden.

Van, H., (1992) "Ecological Modelling in GIS" Department of Environmental Studies, University of Utrecht, The Netherlands

Woods, C., (2003), “Environmental Impact Assessment: A Comparative Review” Malaysia Pearson Education.

Xiong, D., Russell, L. and Bo, J., (2002) "Remote Sensing Applications for Environmental Analysis in Transportation Planning: Application to the Washington State I-405 Corridor at Oakridge". 
